\title{
PKC乙 facilitates lymphatic metastatic spread of prostate cancer cells in a mice xenograft model
}

\author{
Guangxiang Zang ${ }^{1} \cdot$ Yabing $\mathrm{Mu}^{1} \cdot \operatorname{Linlin} \mathrm{Gao}^{1,2} \cdot$ Anders Bergh $^{1} \cdot$ Marene Landström (i) $^{1}$
}

Received: 14 November 2017 / Revised: 20 November 2018 / Accepted: 15 January 2019 / Published online: 31 January 2019

(c) The Author(s) 2019. This article is published with open access

\begin{abstract}
Prostate cancer disseminates primarily into the adjacent lymph nodes, which is related to a poor outcome. Atypical protein kinase $\mathrm{C} \zeta(\mathrm{PKC} \zeta)$ is highly expressed in aggressive prostate cancer and correlates with Gleason score, clinical stage, and poor prognosis. Here, we report the molecular mechanisms of PKC $\zeta$ in lymphatic metastasis during prostate cancer progression. Using zinc-finger nuclease technology or PKC $\zeta$ shRNA lentiviral particles, and orthotopic mouse xenografts, we show that PKC $\zeta$-knockout or knockdown from aggressive prostate cancer (PC3 and PC3U) cells, decreasesd tumor growth and lymphatic metastasis in vivo. Intriguingly, PKC -knockout or knockdown impaired the activation of AKT, ERK, and NF-KB signaling in prostate cancer cells, thereby impairing the expression of lymphangiogenic factors and macrophage recruitment, resulting in aberrant lymphangiogenesis. Moreover, $\mathrm{PKC} \zeta$ regulated the expression of hyaluronan synthase enzymes, which is important for hyaluronan-mediated lymphatic drainage and tumor dissemination. Thus, PKC $\zeta$ plays a crucial oncogenic role in the lymphatic metastasis of prostate cancer and is predicted to be a novel therapeutic target for prostate cancer.
\end{abstract}

\section{Introduction}

Prostate cancer is the most prevalent cancer and second leading cause of cancer death in men. A total of 180,890 new cases of prostate cancer and 26,120 deaths from this disease were reported in the United States in 2016 [1]. Frequently, prostate cancer cells metastasize into adjacent lymph nodes and bone. Lymph node metastasis often indicates a poor prognosis for prostate cancer patients and, if present, has only 20-30\% 5-year survival in patients with more than five metastatic lymph nodes and 75-80\% 5-year survival in patients with a single metastatic lymph node [2].

These authors contributed equally: Guangxiang Zang, Yabing $\mathrm{Mu}$

Supplementary information The online version of this article (https:// doi.org/10.1038/s41388-019-0722-9) contains supplementary material, which is available to authorized users.

Marene Landström

Marene.Landstrom@umu.se

1 Department of Medical Biosciences, Building 6M, 2:nd floor, Umeå University, SE 90185 Umeå, Sweden

2 Present address: National Institute of Biological Sciences, 7 Science Park Road ZGC Life Science Park, Beijing 102206, China
Lymph node metastasis also indicates a lower possibility of success for therapeutic treatment of prostate cancer [3]. Therefore, understanding mechanisms behind the lymphatic metastasis of prostate cancer is crucial.

$\mathrm{PKC}$, a member of the atypical protein kinase $\mathrm{C}(\mathrm{aPKC})$ subfamily, is a calcium- and diacylglycerol-independent serine/threonine-protein kinase [4] that promotes the aggressive phenotype of human prostate cancer. PKC $\zeta$ expression is highly correlated with Gleason score, clinical stage, and poor survival [5] and enhanced expression of PKC $\zeta$ has also been reported in breast [6], glioma [7, 8], and pancreatic cancer [9]. Via different signaling pathways, PKC $\zeta$ plays a crucial role in the regulation of multiple cellular processes. In mitogen-activated protein kinase (MAPK) cascades, PKC $\zeta$ functions as a MEK1 kinase, activating MEK1 and ERK1 upon stimulation with serum or tumor necrosis factor $\alpha(\mathrm{TNF} \alpha)$ [10]. PKC $\zeta$ also acts as an adaptor protein in the activation of MEK5-ERK5 in the EGF signaling pathway, regulating cell proliferation [11]. Notably, $\mathrm{PKC} \zeta$ is active upstream of the inhibitor of nuclear factor-kappa-B (NF-kB) kinase (IKK) pathway, regulating the activation and translocation of NF- $\mathrm{\kappa B}$ dimer p50/p65 into the nucleus. Thus, $\mathrm{PKC} \zeta$ is critically involved in the activation of NF- $\mathrm{KB}$ in the Toll-like receptor (TLR) signaling pathway, which is important for regulation of the 
inflammatory response [12, 13] and cancer progression. $\mathrm{PKC} \zeta$ is also a well-known polarity protein, comprising partition-defective 6 (PAR6) and PAR3, regulating cell polarity, cell migration, and invasion [14].

The tumor microenvironment plays an important role in modulating cancer cell survival, proliferation, and invasion. During tumor progression, a variety of stromal cells in the surrounding environment, such as endothelial cells derived from the bone marrow, are recruited to tumors by cancer cells to construct the blood and lymphatic circulatory system. The inductions of angiogenesis and lymphangiogenesis are crucial for tumor growth and tumor metastatic dissemination. Tumor cells express a number of angiogenic and lymphangiogenic factors to induce the process of angiogenesis and lymphangiogenesis. Importantly, a large number of peripheral blood monocytes from the circulation are also recruited to metastatic sites and differentiate into tumor-associated macrophages (TAMs), promoting lymphangiogenesis, seeding and persistent growth of tumor cells [15-17].

Hyaluronan (HA), a dominant component of the extracellular matrix, is a high molecular weight glycosaminoglycan consisting of a repeated disaccharide. HA is synthesized at the plasma membrane by the hyaluronan synthase enzymes (HASs) and released into the extracellular space. Extracellular HA is subjected to degradation by hyaluronidases (Hyals), and then removed via lymphatic drainage or recycled by resident cells. HA interacts with cell surface receptors, including LYVE-1, CD44, receptor for HA-mediated motility (RHAMM), HA receptor for endocytosis (HARE), intercellular adhesion molecule-1 (ICAM1), and TLR4, which can initiate several signal transduction pathways $[18,19]$. HA plays a critical role in homeostasis, tissue injury and repair, and cancer progression, including the prostate [20]. Lymphatic vessels drain a large number of HA molecules via its receptor LYVE-1 and, by collecting protein-rich fluid and cells, maintain tissue homeostasis, which also facilitates the dissemination of cancer cells [21]. However, little is known about the mechanism whereby prostate cancer cells metastasize via the lymphatics.

In the present study, we investigated the role of $\mathrm{PKC} \zeta$ in lymphatic metastatic spreading during prostate cancer progression. Our results showed that $\mathrm{PKC} \zeta$-knockout in aggressive human prostate cancer (PC3 and PC3U) cells reduces lymphatic metastasis in vivo. Intriguingly, $\mathrm{PKC} \zeta$ knockout inhibited the activation of the AKT, ERK, and NF- $\mathrm{KB}$ signaling pathways in prostate cancer and lung carcinoma (A549) cells. Moreover, we found that PKC $\zeta$ regulates the expression of lymphangiogenic factors and the secretion of CCL2 by prostate cancer cells, which is important for the recruitment of monocytes/macrophages and lymphangiogenesis. Furthermore, we found that PKC $\zeta$ regulates the expression of HASs in prostate cancer cells, which is important for HA production and cancer cell dissemination via lymphatic drainage.

\section{Results}

\section{Expression of PKCC and the response of PKCC inhibitior in prostate cell lines}

The protein expression levels of PKC $\zeta$ was investigated by immunoblotting in non-malignant human prostate cell line RWPE1 and human prostate cancer cell lines LNCaP, PC3 and PC3U. The highly aggressive PC 3 and PC $3 \mathrm{U}$ cells expressed higher levels of $\mathrm{PKC} \zeta$ than the non-malignant RWPE1 and LNCaP cells (Fig. 1a). We next analyzed the capability of proliferation for PC $3 \mathrm{U}, \mathrm{PC} 3$, and LNCap cells in real-time in a xCelligence-based cell proliferation assay. The aggressive $\mathrm{PC} 3 \mathrm{U}$ and $\mathrm{PC} 3$ cells proliferated faster than the less malignant LNCaP cells (Fig. 1b). To investigate if PKC $\zeta$ expression could affect the invasiveness of several types of prostate cells and the highly aggressive lung cancer A549 cells, we treated cells with the inhibitor of $\mathrm{PKC} \zeta$,

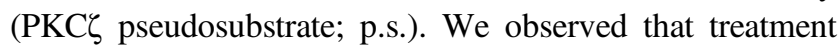
with $\mathrm{PKC} \zeta$ inhibitor significantly reduced invasion of $\mathrm{PC} 3 \mathrm{U}$, A549 and PC3 cells (Fig. 1c, d). We also observed that PC3U cells showed higher invasive capability than PC3 cells (Fig. 1c, d), which was reflected by the higher number of mutated genes in PC3U cells, as found by performing whole genomic sequencing (Supplementary Figure 1A and Fig. 1B). Interestingly, treatment with $\mathrm{PKC} \zeta$ pseudosubstrate, could also inhibit the proliferation of PC $3 \mathrm{U}$ and PC3 cells, but not LNCaP cells as investigated by a xCelligence proliferation assay (Fig. 1e-g). The proliferation of PC3U and PC 3 cells was significantly inhibited by treatment with the $\mathrm{PKC} \zeta$ pseudosubstrate in a dose-dependent manner (5 $\mu \mathrm{M}$ and $10 \mu \mathrm{M}$ ), compared with control (Fig. 1e, f). In contrast, treatment of LNCaP cells with $\mathrm{PKC} \zeta$ pseudosubstrate did not cause inhibition of their proliferative capability (Fig. 1g). From these data, we concluded that the expression of PKC $\zeta$ was higher in the most aggressive prostate cancer cells (PC3 and PC3U) and correlated with their proliferative and invasive capability, as treatment with $\mathrm{PKC} \zeta$ pseudosubstrate significantly reduced both proliferation and invasion. LNCaP cells with lower levels of PKC $\zeta$ showed less capability to invade and their proliferation which was not affected by treatment with $\mathrm{PKC} \zeta$ pseuodsubstrate.

\section{Generation and validation of PKC - deficient cancer cells}

The programmable nucleases, such as zinc-finger nucleases (ZFNs), transcription activator-like effector nucleases (TALENs), and clustered regularly interspaced short 
Fig. 1 Expression of $\mathrm{PKC} \zeta$ and the response for $\mathrm{PKC} \zeta$ inhibitor in prostate cell lines. a Western blot analysis of PKC $\zeta$

expression in non-malignant human prostate cell line RWPE1 and human prostate cancer cell lines LNCaP, PC3 and PC3U. $\mathrm{PKC} \zeta$ and $\beta$-tubulin antibodies were used at 1:1000 dilution. Bar graph represents the mean \pm S.D. of 3 independent experiments, $* p \leq 0.05$, students' $t$ test. b Proliferation of PC3U, PC3, and LNCap cells was monitored by a real-time xCelligence-based cell proliferation assay. Representive results from 3 independent experiments are shown as mean \pm S.D., $* * * p \leq 0.001$ as determined by students' $t$ test. c Invasion assay for PC3U, A549, $\mathrm{PC} 3$, and $\mathrm{LNCaP}$ cells treated with $\mathrm{PKC} \zeta$ pseudosubstrate (PKCל p.s.) or not. Invasive cells were visualized by staining with crystal violet cell stain solution. Scale bar, $50 \mu \mathrm{m}$. d Mean values for the optical density (OD) of invasive cells. Error bar represents S.D. $(n=3$ independent experiments, ${ }^{*} p \leq$ $0.05, * * * p \leq 0.001$, one-way ANOVA. e-g xCelligencebased cell proliferation assay for PC3U, PC3, and LNCap cells treated with $\mathrm{PKC} \zeta$ p.s. or not. Representive results from 3 independent experiments are shown as mean \pm S.D. $* * * p \leq$ 0.001 as determined by students' $t$ test a

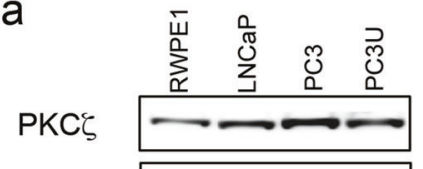

$\beta$-tubulin

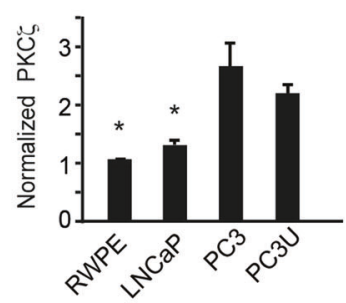

b

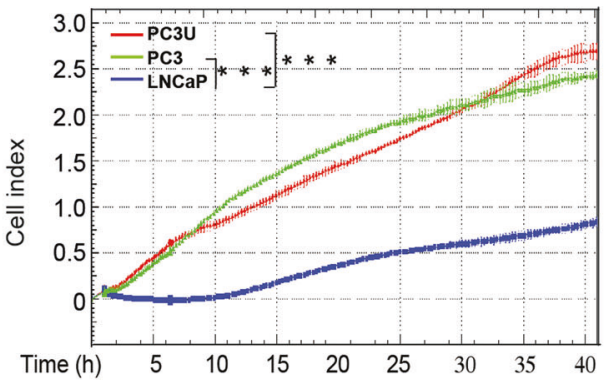

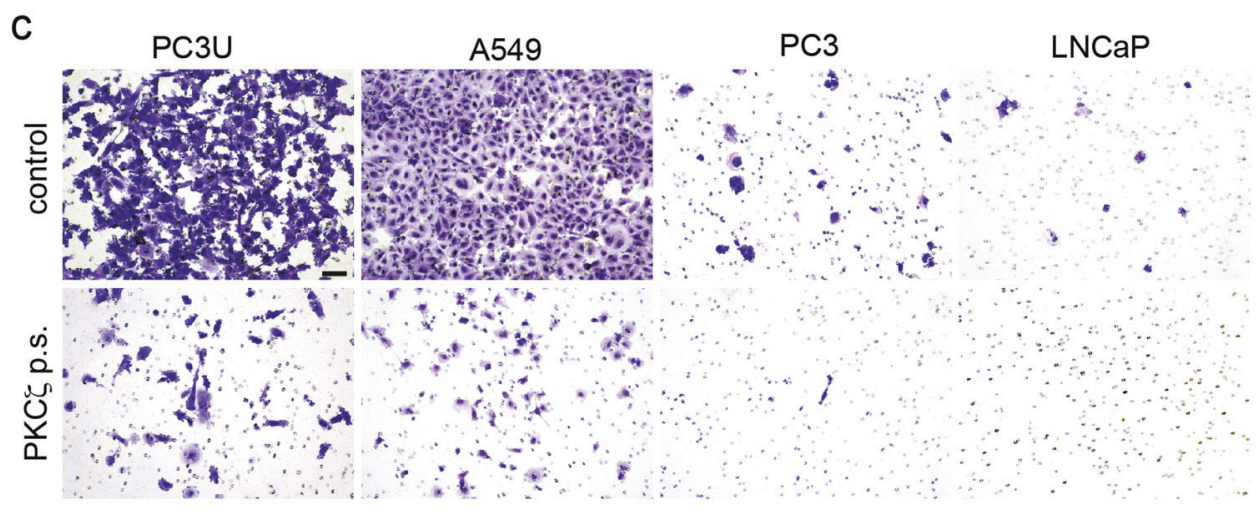
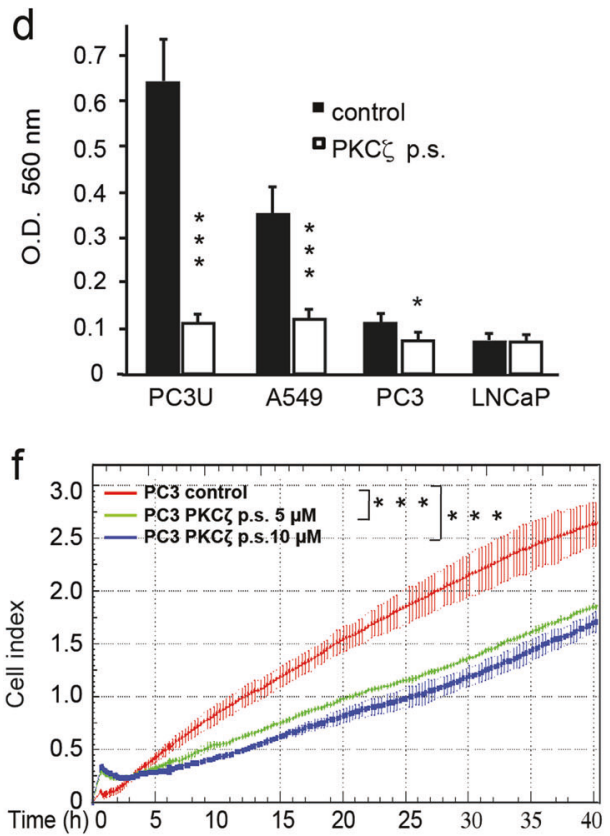

e
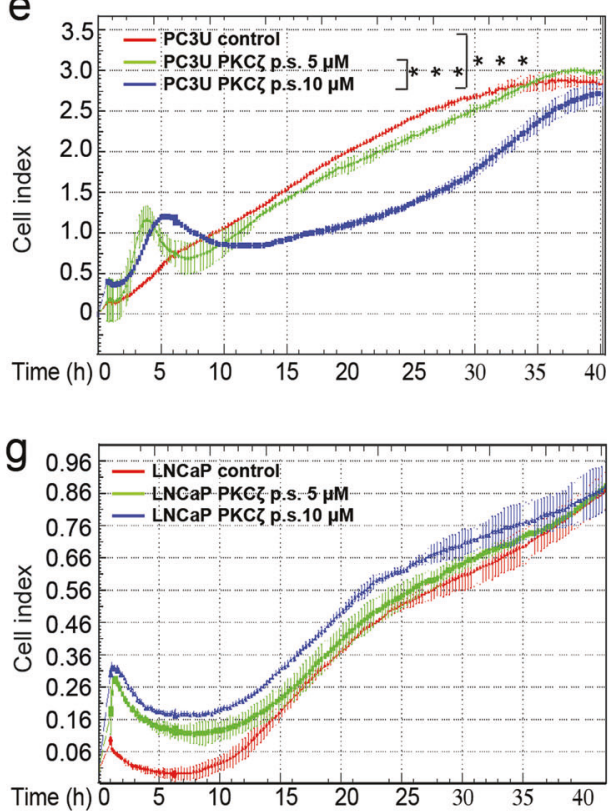

palindromic repeat/CRISPR-associated protein 9 (CRISPR/ Cas9), have been widely used for genetic manipulation in different model systems [22-24]. In our study, CompoZrZFNs were used for specific gene disruptions. One pair of knockout ZFN plasmids that specifically target the $P K C \zeta$ gene were purchased from Sigma-Aldrich. Following the protocol, the $P K C \zeta$ gene was knocked out in PC3U cells. Two cell clones were selected: 9A, which has one base-pair deletion, and 26A, which has eight base-pair deletions in the $P K C \zeta$ gene (Fig. 2a-c). The $P K C \zeta$ gene from WT cells, clone 9A, and clone 26A was amplified by PCR and detected by Single-Strand Conformation Polymorphism 
a

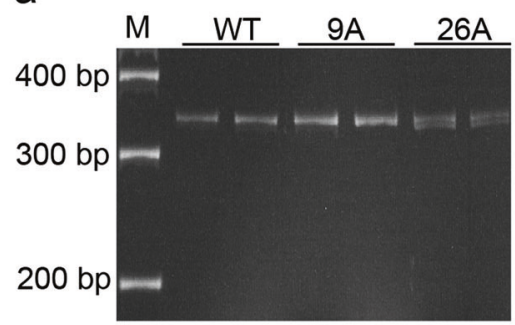

C

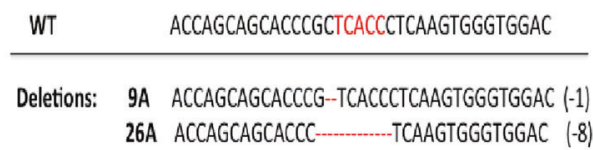

e

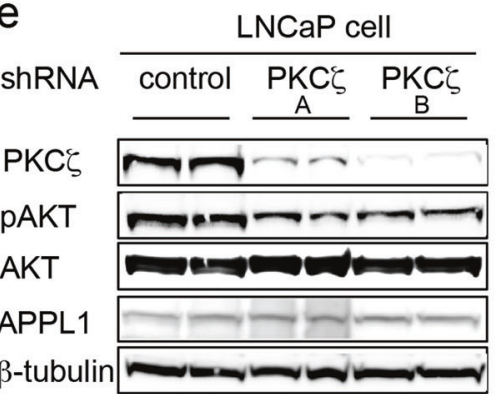

Fig. 2 Generation and validation of $\mathrm{PKC}$-deficient cancer cell lines. a PKC $\zeta$ gene was knockout in PC3U cells by Zinc Finger Nucleases (ZFN) technology, and $\mathrm{PKC} \zeta$ gene from WT and $\mathrm{PKC} \zeta$-knockout clones 9A and 26A was amplified by PCR and detected by Singlestrand conformation polymorphrism (SSCP) analysis. PKC $\zeta$ gene mutations were identified by Cel-I (Surveyor nuclease) assay. Arrows indicate the cleavage products generated in Surveyor nuclease assays. c Representative sequencing analysis for $\mathrm{PKC} \zeta$ gene deletion induced b

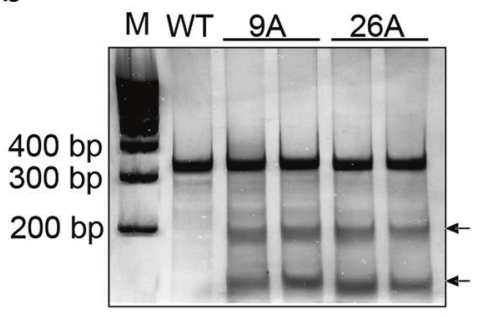

d

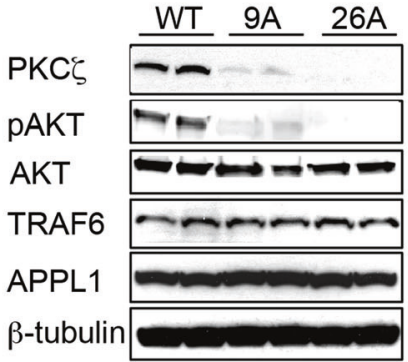

by ZFN. The red letters represent ZFN-binding sites, and the red dashes represent the deletions in $\mathrm{PKC} \zeta$ gene. $\mathbf{d}$ Western blot analysis of PKC $\zeta$ and other proteins expressed in WT PC3U cells, and clones 9A and 26A. e LNCaP cells were stably transfected with control shRNA or PKC $\zeta$ shRNA lentiviral particles $(\mathrm{A}=10 \mu \mathrm{l} / \mathrm{ml}, \mathrm{B}=20 \mu \mathrm{l} /$ $\mathrm{ml}$ ), and the total cell lysates were subjected to western blot analysis. Antibodies were used at 1:1000 dilution $(\mathbf{d}, \mathbf{e})$
(SSCP) analysis (Fig. 2a). SURVEYOR mutation detection (CEL-1) assay was performed to detect the double-stranded DNA mismatches in 9A and 26A (Fig. 2b), which indicate deletions in the PKC $\zeta$ gene in the cell clones. The results were verified by DNA sequencing and whole exome sequencing (Fig. 2c). Immunoblotting showed that the PKC $\zeta$ protein level was clearly decreased (Fig. 2d), whereas other proteins, such as the ubiquitin ligase TRAF6 and endocytic adaptor protein APPL1, were not affected. Interestingly, activation of AKT was prevented when the $\mathrm{PKC} \zeta$ gene was knocked out in the 9A and 26A cell clones. We investigated also the role for $\mathrm{PKC} \zeta$ on AKT activation in LNCaP cells by knock down of PKC $\zeta$ by stable transfection of shRNA lentiviral particles, but only a modest effect was found when compared with control shRNA cells when total cell lysates were investigated by immunoblot for p-AKT (Fig. 2e). From these data we concluded that knock down of $\mathrm{PKC} \zeta$ in $\mathrm{PC} 3 \mathrm{U}$ cells had a more obvious effects to reduce the activity status of AKT than in $\mathrm{LNCaP}$ cells, in line with the higher expression of $\mathrm{PKC} \zeta$ in $\mathrm{PC} 3 \mathrm{U}$ cells (as shown in Fig. 1).

\section{Knockout or knockdown of PKC乙 inhibits activation of AKT, ERK and NF-KB signaling}

Previous studies have shown that PKC $\zeta$ is involved in the EGF, TGF $\beta$, and Toll-like receptor (TLR) signaling pathways $[10,12,13,25]$ thus, it was interesting to elucidate the impaired signaling induced by reduced $\mathrm{PKC} \zeta$ expression in PC3U cells.

First, the effects on the EGF signaling pathway were investigated, showing that the activation of AKT and ERK were inhibited when $P K C \zeta$ was knocked out in $26 \mathrm{~A}$ cell clones (Fig. 3a). Second, TGF $\beta$ is known to activate AKT in WT PC3U cells [25], but activation of AKT was observed to be reduced in 26A cells (Fig. 3b). Third, the activation of 
Fig. 3 Knockout or knockdown of $P K C \zeta$ inhibited activation of AKT, ERK and NFKB signaling. a Western blot analysis of WT and $P K C \zeta$ knockout $26 \mathrm{~A}$ cells treated with EGF, (b) TGF $\beta$, (c) $\mathrm{TNF} \alpha$ for the indicated time. Bar graph represents the mean \pm S.D. of 3 independent experiments, $* p \leq 0.05$, students' $t$ test. d $P K C \zeta$ was stably knocked down in PC3 cells and (e) A549 cells by $\mathrm{PKC} \zeta$ shRNA lentiviral particles, and the total cell lysates were subjected to western blot analysis. Bar graph represents the mean \pm S.D. of 3 independent experiments, $* p \leq$ 0.05 , students' $t$ test. Antibodies were used at 1:1000 dilution a
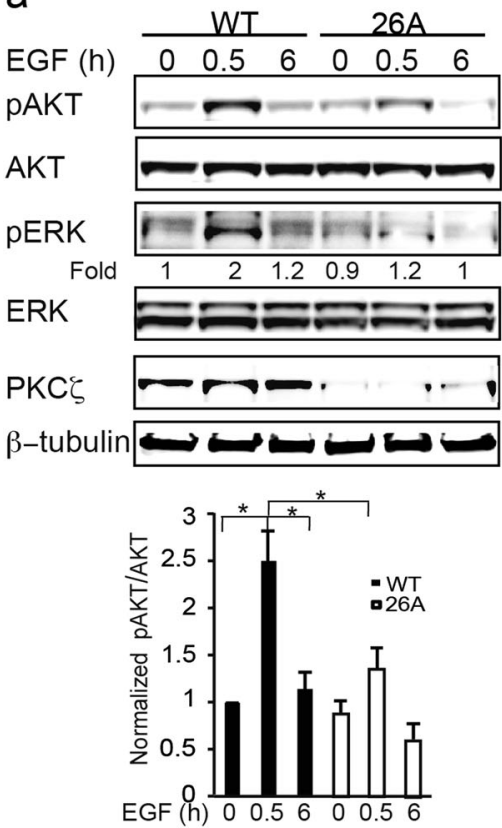

b

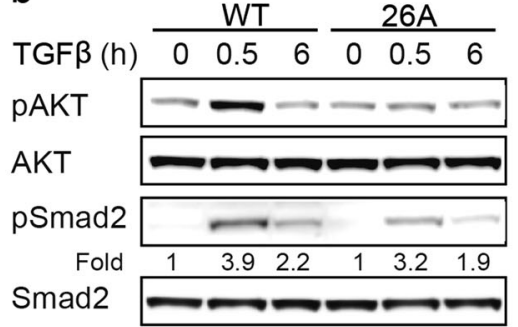

PKC

$\beta$-tubulin
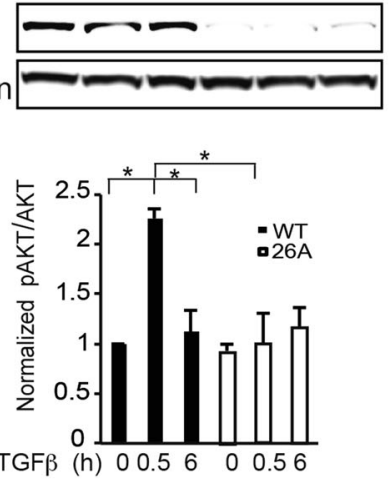

C
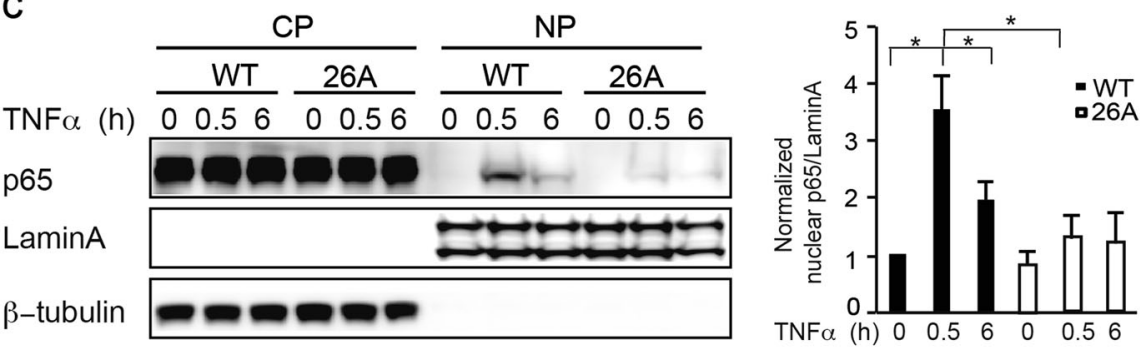

d
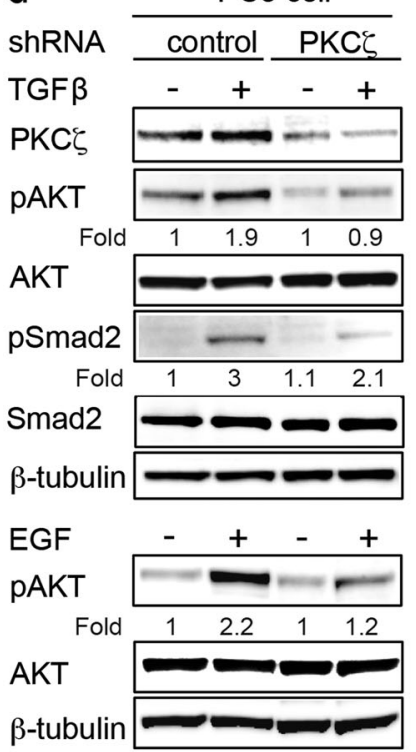

e ShRNA EGF (h) \begin{tabular}{lllllll}
\cline { 2 - 3 } & 0.5 & 6 & 0 & 0.5 & 6
\end{tabular} PKC $\zeta$ pAKT AKT $\beta$-tubulin

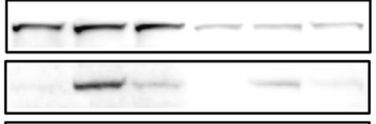

A549 cell
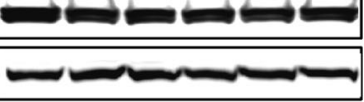

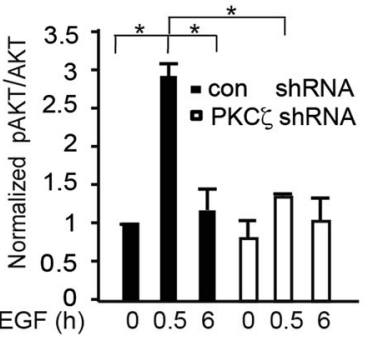

$\mathrm{NF}-\kappa \mathrm{B}$ signaling was investigated by immunoblotting the cytoplasmic and nuclear fractions; p65 was activated and translocated into the nuclei of WT PC3U cells upon TNF $\alpha$ stimulation, whereas less p65 was found in the nuclear fraction from 26A cells (Fig. 3c). Next we extended our study on the effects of PKC $\zeta$ for selected intracellular 
Fig. 4 Knockout or knockdown of $\mathrm{PKC} \zeta$ in cancer cells impairs cell proliferation and invasion. a Immunofluorescence analysis of Ki-67 in WT PC3U cells and the PKC $\zeta$-knockout clones 26A.

Scale bar, $50 \mu \mathrm{m}$. b

Quantification of Ki-67-positive cells in total 300 cells. Bar graph represents as mean \pm S.D. from 3 independent experiments, ${ }^{*} p \leq$

0.05 , students' $t$ test. c Invasion assay for WT PC3U and the $P K C \zeta$-knockout clones 26A cells, and the invasive cells were visualized by staining with crystal violet cell stain solution. Scale bar, $50 \mu \mathrm{m}$. d Mean optical density (O.D.) of invasive cells. Bar graph represents the mean \pm S.D. of 3 independent experiments, * $p \leq 0.05$, students' $t$ test. e Immunofluorescence analysis of Ki-67 in A549 cells stably transfected with control shRNA or PKC $\zeta$ shRNA lentiviral particles. Scale bar, 50 $\mu \mathrm{m}$. f Quantification of Ki-67positive cells in more than 300 cells. Bar graph represents the mean \pm S.D. of 3 independent experiments, ${ }^{*} p \leq 0.05$, students' $t$ test. g Invasion assay for A549 cells treated with control shRNA or PKC $\zeta$ shRNA lentiviral particles, and the invasive cells were visualized by staining with crystal violet cell stain solution. Scale bar, $50 \mu \mathrm{m}$. h Mean optical density (O.D.) of invasive cells. Bar graph represents the mean and S.D. of 3 independent experiments, ${ }^{*} p \leq 0.05$, students' $t$ test. Antibodies for $\mathrm{Ki}-67$ were used at 1:500 dilution $(\mathbf{a}, \mathbf{e})$ a
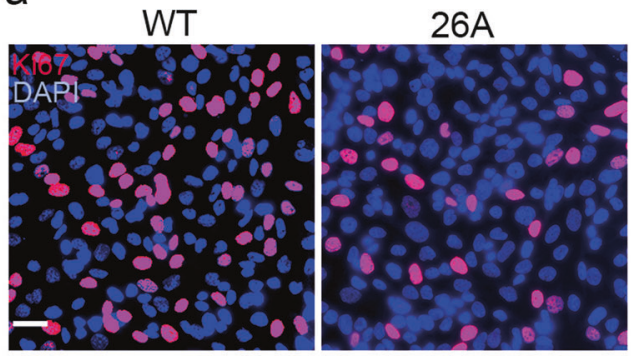

C

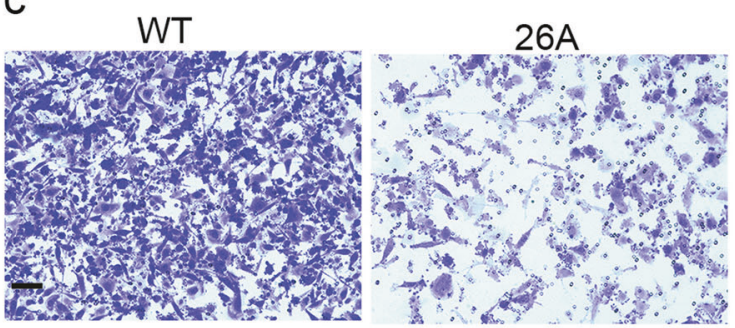

e
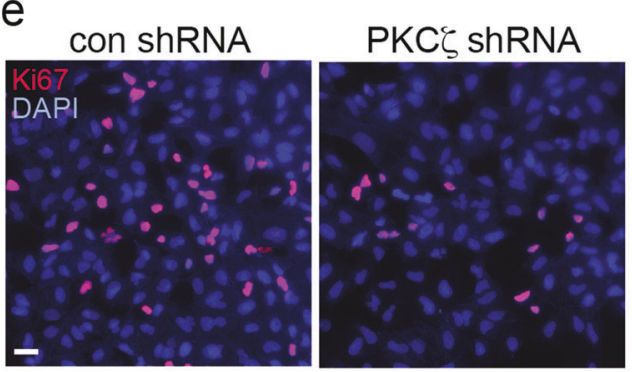

g

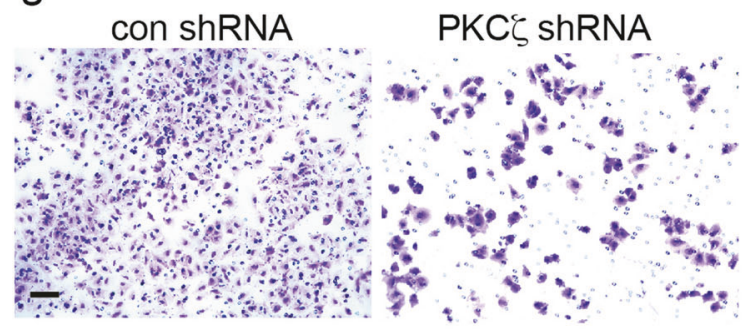

b

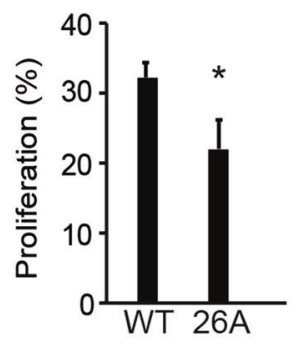

d

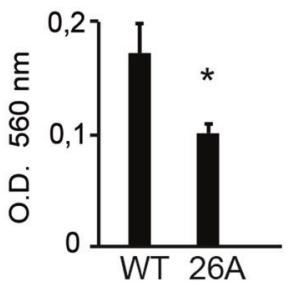

f

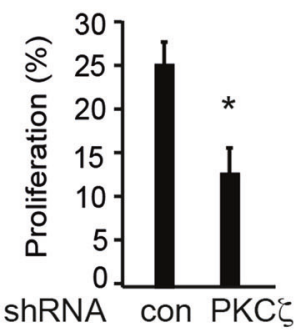

h

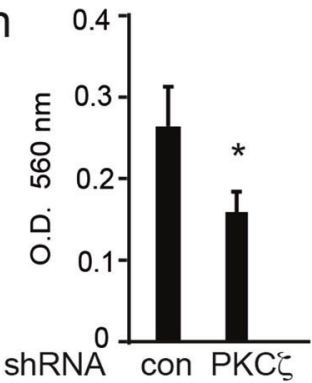

signaling pathways to include PC3 cells (Fig. 3d) and A549 cells (Fig. 3e) in which $P K C \zeta$ was stably knocked down by using PKC $\zeta$ shRNA lentiviral particles. Immunoblotting was used to analyze the role of $\mathrm{PKC} \zeta$ for activation of AKT and Smad2 in response to TGF $\beta$ (Fig. 3d) or AKT in response to EGF (Fig. 3e). Upon TNF $\alpha$ stimulation, it was also observed that less p65 was activated and translocated into the nuclei when $P K C \zeta$ was stably knocked down in PC3 cells by immunofluorescence staining (Supplementary Figure 2). These data indicated that knocking out PKC $\zeta$ in PC3U, PC3 and A549 cells inhibited growth factor induced activation of the AKT, ERK, and NF- $\mathrm{KB}$ signaling pathways, which is important for regulation of cell proliferation and invasion in prostate cancer progression.

\section{Knockout or knockdown of $P K C \zeta$ in cancer cells impairs cell proliferation and invasion}

Since we observed that knock down of $P K C \zeta$ affected growth factor induced activation of several key intracellular signaling pathways, we investigated next the biological relevance of these observation by analyzing their eventual effects on proliferation and invasion. Reduced proliferation as measured by $\mathrm{Ki}-67$, and invasion was observed in the PKC $\zeta$-knockout clones 26A compared with WT PC3U cells (Fig. 4a-d). Knock down of PKC $\zeta$ in A549 cells by PKC $\zeta$ shRNA lentiviral particles in comparision with control shRNA, impaired also their capability to proliferate and be invasive (Fig. 4e-h). From these data we conclude that 
a

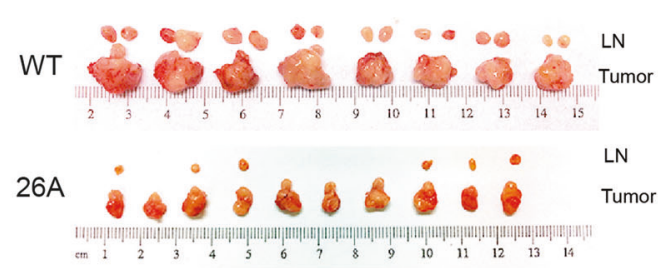

e

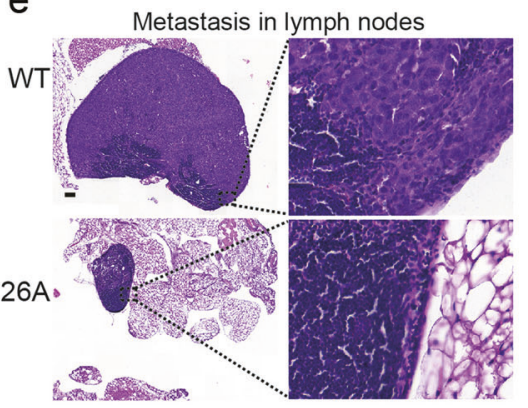

f

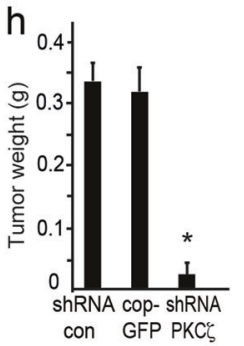

$\mathrm{k}$

con ShRNA

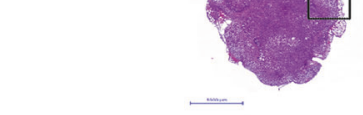

copGFP

PKC $\zeta$ shRNA
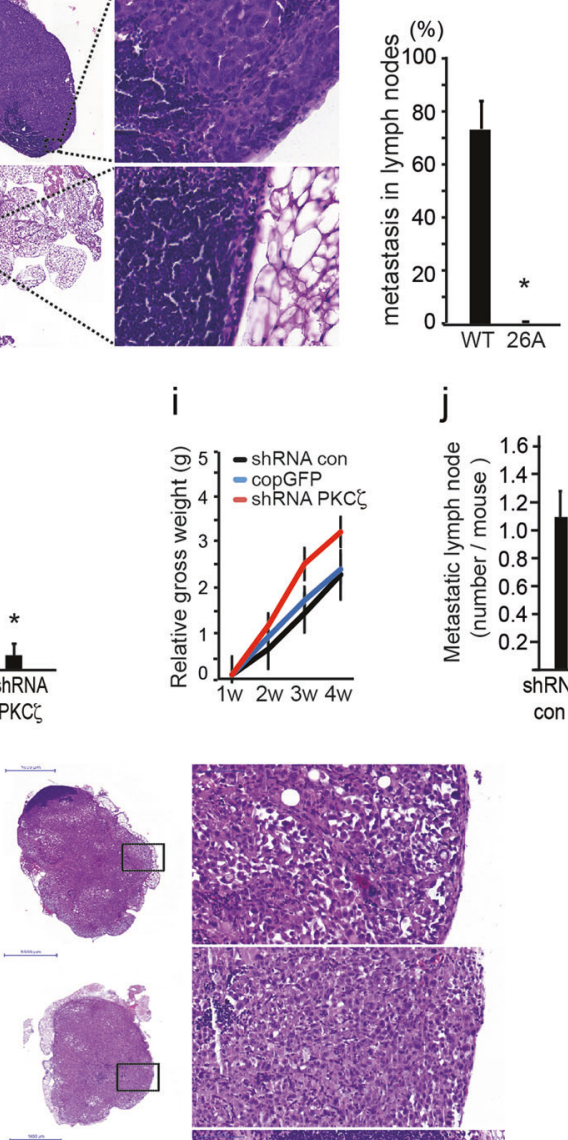

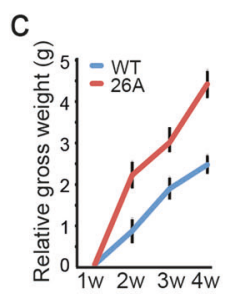

d

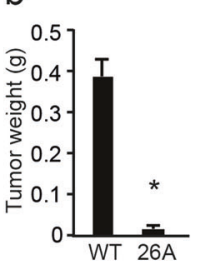

g

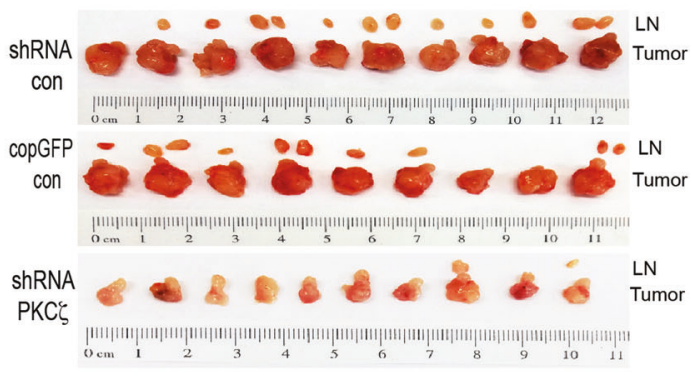

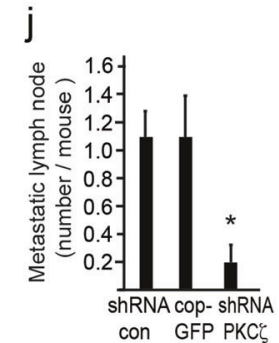

।

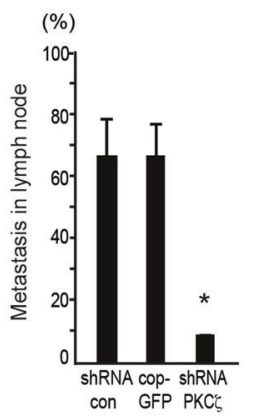

expression of $\mathrm{PKC} \zeta$ is important for growth factor induced proliferation and invasion of prostate and lung cancer cells.

\section{Knockout or knockdown of PKC乙 reduces tumor growth and lymphatic metastasis in an orthotopic xenograft model}

To investigate the role of $\mathrm{PKC} \zeta$ in prostate cancer progression in vivo, we performed animal experiments via orthotopic implantation of WT PC $3 \mathrm{U}$ cells or $P K C \zeta$ knockout cells (26A) into the ventral prostate of nude mice.
Compared to the WT cells, 26A cells developed into smaller tumors and had less metastasis into adjacent regional lymph nodes (Fig. 5a). The net weight of the formed tumors was significantly reduced in 26A (Fig. 5b), and the mice in the 26A group apparently gained more body weight than the WT group, due to the mouse in the WT group suffered from a larger tumor burden (Fig. 5c). Importantly, markedly fewer metastatic lymph nodes (Fig. 5a, d) and less lymphatic dissemination were detected in mice implanted with the $26 \mathrm{~A}$ cell clone (Fig. 5a, e, f, g). The metastatic lymph nodes were examined and found to be much larger and 
Fig. 5 Knockout or knockdown of $P K C \zeta$ inhibits tumor growth and lymphatic metastasis in an orthotopic xenograft mouse model. a WT PC3U and PKC $\zeta$-knockout 26A cells were injected into the prostate of mice. Tumors and the regional lymph nodes (LNs) were obtained after 4 weeks, WT tumor $n=8$, LN $n=16$; 26A tumor $n=10$, LN $n=6$. b Mean value of tumor weight \pm S.E.M. for WT $(n=8)$ and 26A group $(n=10), * p \leq 0.05$, Mann-Whitney non-parametric test. c Analysis of the gain of body weight in mice with tumor burden by measuring the mouse's gross weight during tumor growth. Bar graph shows the mean \pm S.E.M. from WT $(n=8)$ and 26A $(n=10)$ group. $* p \leq 0.05$, students' $t$ tests. d Quantification of metastatic LNs shows mean \pm S.E. M from WT $(n=8)$ and 26A $(n=10),{ }^{*} p \leq 0.05$, Mann-Whitney nonparametric test. e Representative images of metastatic lymph nodes by Hematoxylin-eosin (H\&E) staining. Scale bar, $200 \mu \mathrm{m}$. f Quantification of the invasive area occupied by cancer cells in the LNs. Bar graph shows the mean \pm S.E.M. from WT $(n=16)$ and 26A $(n=6)$, * $p \leq 0.05$, Mann-Whitney non-parametric test. g PC3 cells, stably transfected with control shRNA, cop GFP control, or PKC $\zeta$ shRNA lentiviral particles, were injected into the prostate of mice, and the tumors and the regional lymph nodes (LNs) were collected after 6 weeks, con shRNA group $n=10, \mathrm{LN} n=12$; cop GFP group: tumor $n=9$, LN $n=10$; PKC $\zeta$ shRNA group $n=10$, LN $n=2$. h Mean value of tumor weight \pm S.E.M. for con shRNA $(n=10)$, cop GFP control $(n=9)$, and PKC $\zeta$ shRNA group $(n=10), * p \leq 0.05$, MannWhitney non-parametric test. i Analysis of the gain of body weight in mice with tumor burden by measuring the mouse's gross weight during tumor growth. Bar graph shows the mean \pm S.E.M. from con shRNA $(n=10)$, cop GFP control $(n=9)$, and PKC $\zeta$ shRNA group $(n=10)$. j Quantification of metastatic LNs shows mean \pm S.E.M. from con shRNA $(n=10)$, cop GFP control $(n=9)$, and PKC $\zeta$ shRNA group $(n=10)$. $* p \leq 0.05$, Mann-Whitney non-parametric test. $\mathbf{k}$ Representative images of metastatic lymph nodes by Hematoxylin-eosin (H\&E) staining. Scale bar, $1000 \mu \mathrm{m}$. f Quantification of the invasive area occupied by cancer cells in LNs. Bar graph shows the mean \pm S.E.M. from con shRNA $(n=12)$, cop GFP control $(n=10)$, and PKC $\zeta$ shRNA group $(n=2), * p \leq 0.05$, Mann-Whitney non-parametric test

more invasive in the WT group than the 26A group (Fig. 5e, f). We extended our study to also compromise PC 3 cells, stably transfected with control shRNA, cop GFP control, or PKC $\zeta$ shRNA lentiviral particles, which were injected in the prostate of mice; and the tumors and the regional lymph nodes (LNs) were collected after 6 weeks. A reduction in tumor size and metastasis in lymph nodes were observed by knock down of PKC (Fig. 5g, h), which was reflected in the body weight of the animal (Fig. 5i). Also the number of metastatic lymph nodes and area invaded by cancer cells, was significantly reduced in the $P K C \zeta$ knockdown group (Fig. 5j-1). However, in the mouse xenograft model implanted with LNCaP cells, less metastasis was observed in lymph nodes, even in the WT group (Supplementary Figure 3). This is consistent with our observation in vitro that lower level of $\mathrm{PKC} \zeta$ expression and lower invasiveness in $\mathrm{LNCaP}$ cells as shown in Fig. 1. These data are providing evidence for that knocking out $P K C \zeta$ in prostate cancer cells prevented their invasion in vivo. Taken together, our data show that PKC $\zeta$ may regulate tumor growth and invasion in prostate cancer progression in vivo.

\section{PKC乙 facilitates lymphangiogenesis in mouse xenografts}

To further elucidate the role of PKC $\zeta$ in lymphatic metastasis in prostate cancer, we performed immunohistochemistry (IHC) to investigate the lymphatic vessel marker LYVE-1 by staining the tissues dissected from mouse xenografts. Interestingly, a number of lymphatic vessels formed in and around the invasive tumor that developed from WT prostate cancer cells (Fig. 6a), and many vessels were enlarged and irregular, representing the typical remodeling of lymphatic vessels in tumors. However, in the tumors developed from $P K C \zeta$-knockout cell line 26A, there were fewer lymphatic vessels and less lymphatic vessel remodeling. Quantification of the intratumoral and peritumoral lymphatic vessels revealed significantly different lymphatic vessel density between the WT and 26A groups (Fig. 6b). To verify the enlargement of lymphatic vessels in tumors, the area of each lymphatic vessel was measured and quantified. The size (area) of each lymphatic vessel formed in the WT tumors was significantly larger than the lymphatic vessels formed in the 26A group (Fig. 6c). Notably, the invasion of prostate cancer cells into the enlarged modified lymphatic vessels was detected in the WT group (Fig. 6a), but not the $P K C \zeta$-knockout group. We next extended our study to involve the effects of $\mathrm{PKC} \zeta$ also on lymphatic vessels in tumors developed from PC3 cells stably transfected with control shRNA, cop GFP control, or PKC $\zeta$ shRNA lentiviral particles (Fig. 6d-f). Similar effects of knocking down $P K C \zeta$ on the invasiveness of PC3 cells into lymphactic vessels, and the area and size of lymphactic vessels, was observed as in PC3U cells. These data indicate that $\mathrm{PKC} \zeta$ is involved in the regulation of aberrant lymphangiogenesis in prostate cancer progression, and that the intratumoral and peritumoral lymphatics may facilitate the transport of cancer cells to lymph nodes via lymphatic drainage.

\section{PKCZ is involved in the regulation of aberrant lymphangiogenesis and lymphatic metastatic microenvironement}

It is of interest to understand how $\mathrm{PKC} \zeta$ regulates aberrant lymphangiogenesis during tumor progression. Therefore, we investigated the expression of lymphangiogenic factors by performing qRT-PCR of WT PC3U and PKC -knockout cells (clone 26A). Interestingly, the expression of VEGF-A, VEGF-D, ANG1, and ANG4 in WT PC3U cells was apparently higher than in the $26 \mathrm{~A}$ cell clone, whereas no differential expression was found for VEGF-C and FGF2 (Fig. 7a). Monocytes/macrophages are recruited to tumor tissue, and these inflammatory cells are playing an important role in angiogenesis and lymphangiogenesis during 
a

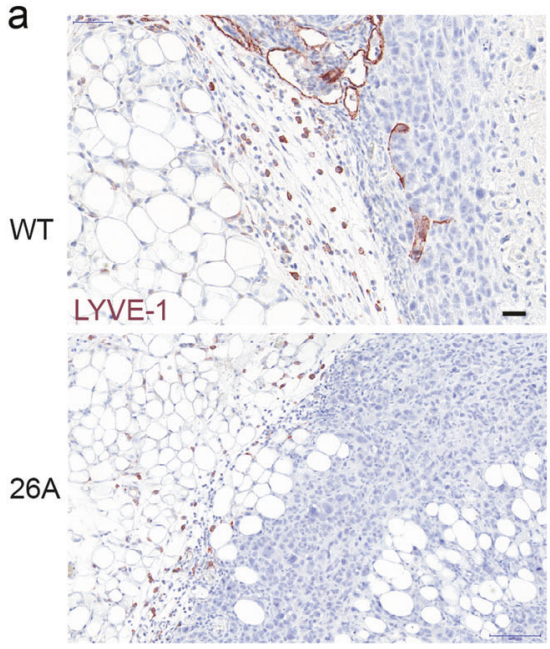

d

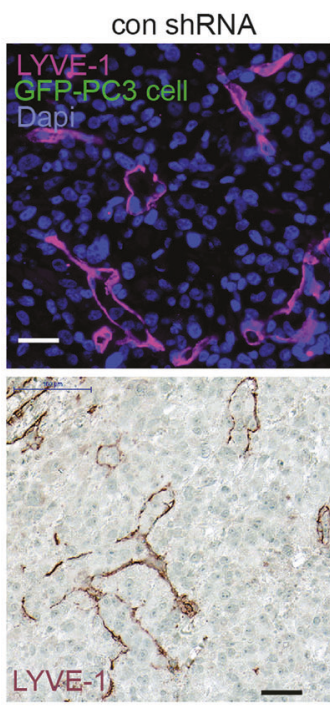

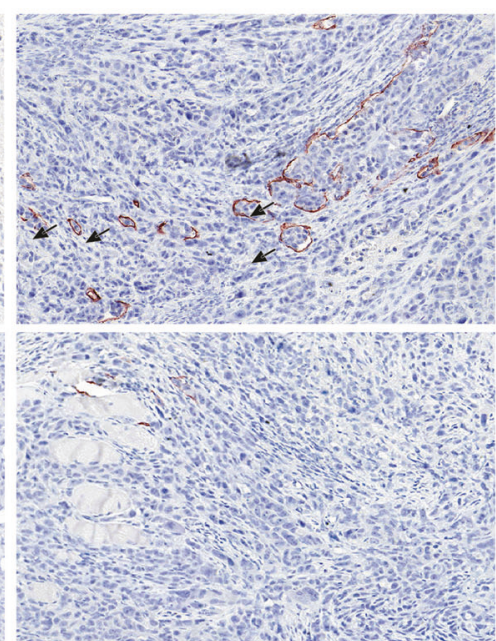
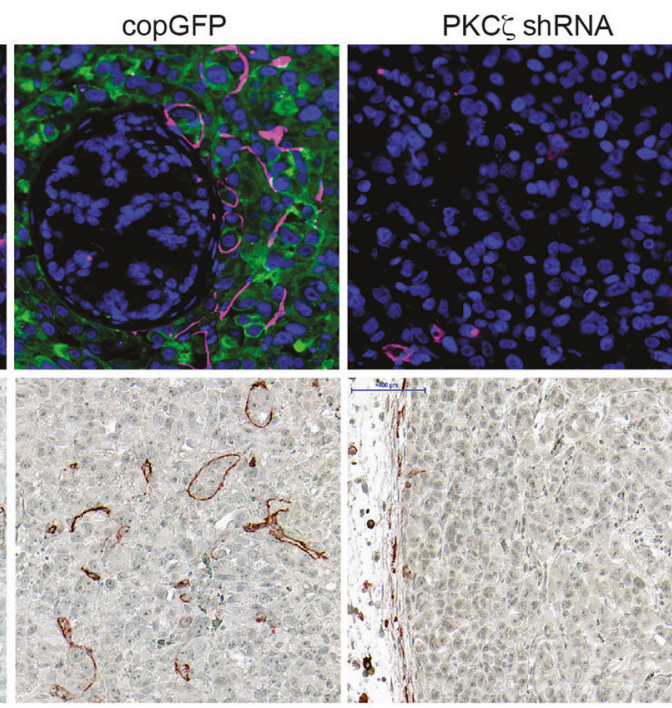

b
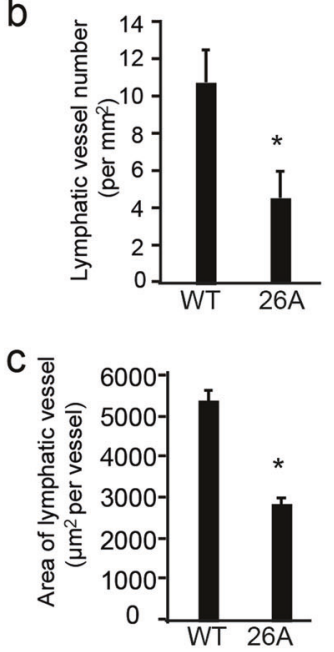

e
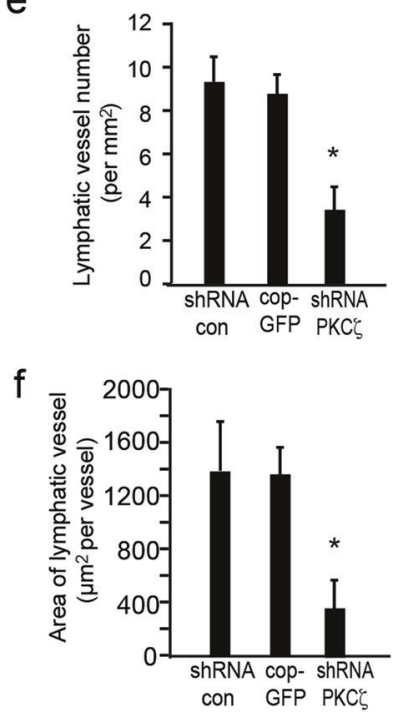

Fig. 6 PKC $\zeta$ facilitates lymphangiogenesis and lymphatic vessel remodeling in mouse xenografts. a Representative images of lymphatic vessels in tumors developed from WT and 26A cells immunohistochemically stained for LYVE-1. Scale bar, $50 \mu \mathrm{m}$. b The number of lymphatic vessels in the images was quantified, given as means \pm S.E.M. for 8 samples ( 8 images) in the WT group and 10 samples (10 images) in the 26A group, ${ }^{*} p \leq 0.05$, Mann-Whitney non-parametric test. c Analysis of the enlarged lymphatic vessel by quantifying the area of each lymphatic vessel. Values are given as means \pm S.E.M. for WT ( 8 images) and $26 \mathrm{~A}(10$ images $),{ }^{*} p \leq 0.05$, Mann-Whitney non-parametric test. d Representative images of lymphatic vessels in tumors developed from PC3 cells stably

tumor progression [26]. Therefore, we further investigated the recruitment of monocytes/macrophages in tumor tissues by immunostaining with mouse macrophage marker F4/80. Remarkably, the number of monocytes/macrophages recruited to the tumors that were initiated from WT PC3U cells was high, and only a few monocytes/macrophages were detected in the tumors initiated from the $26 \mathrm{~A}$ cell clone (Fig. 7b). transfected with control shRNA, cop GFP control, or PKC $\zeta$ shRNA lentiviral particles, immunofluorescence staining (upper panel) immunohistochemistry staining (lower panel) and for LYVE-1. Scale bar, $50 \mu \mathrm{m}$. e The number of lymphatic vessels in the images was quantified, given as means \pm S.E.M. from control shRNA (10 images), cop GFP control (9 images), and PKC $\zeta$ shRNA group (10 images), ${ }^{*} p \leq 0.05$, Mann-Whitney non-parametric test. f Analysis of the enlarged lymphatic vessel by quantifying the area of each lymphatic vessel. Values are given as means \pm S.E.M. from control shRNA (10 images), cop GFP control (9 images), and $\mathrm{PKC} \zeta$ shRNA group (10 images), ${ }^{*} p \leq 0.05$, students' $t$ tests. LYVE- 1 and GFP antibodies were used at 1:200 dilution

We also investigated the chemotactic cytokine $\mathrm{C}-\mathrm{C}$ motif chemokine ligand 2 (CCL2), referred to as monocyte chemoattractant protein 1 (MCP1), which is important for the recruitment of monocytes/macrophages during tumor metastasis [27]. The expression of CCL2 was inhibited when $P K C \zeta$ was knocked out in the $26 \mathrm{~A}$ cell clone (Fig. 7c). CCL2 secreted into the culture media from WT and 26A cells was measured by ELISA. 


\section{a}

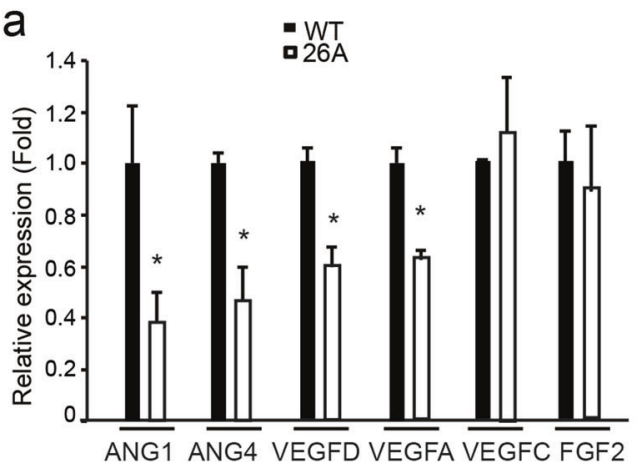

b

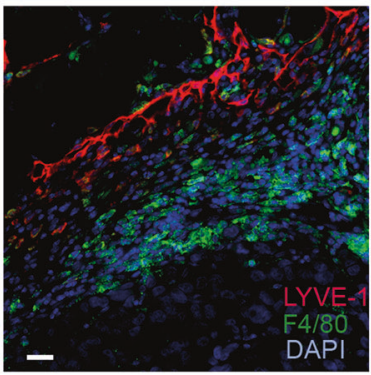

WT

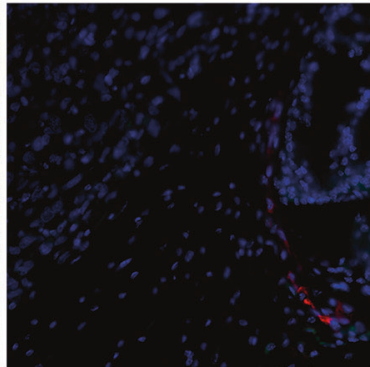

$26 \mathrm{~A}$
C

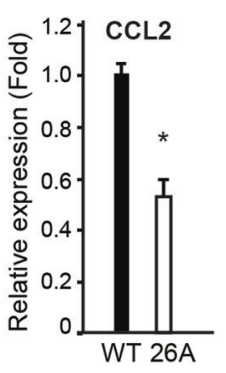

f

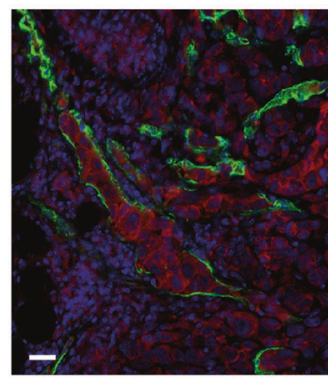

WT

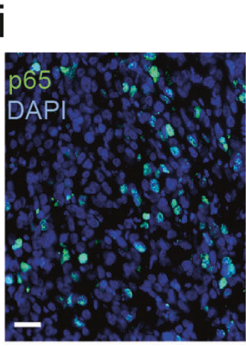

WT d

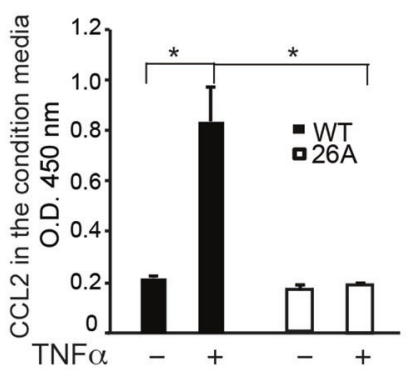

e

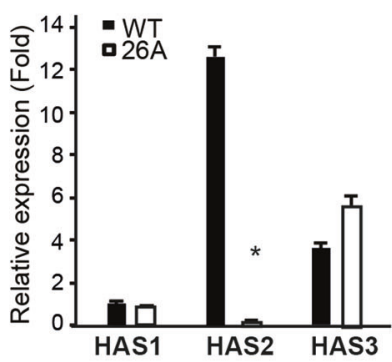

9 - Inside lymphatic vessel - Outside lymphatic vessel

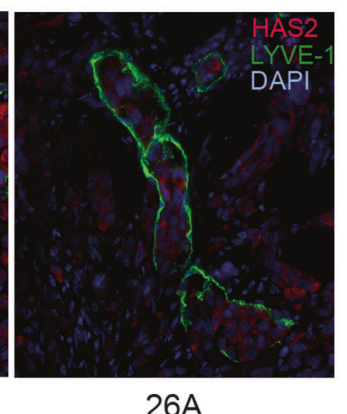

$26 \mathrm{~A}$

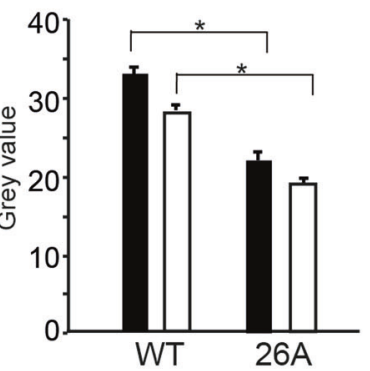

j

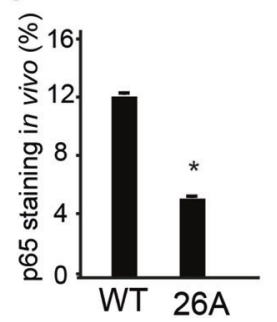

h

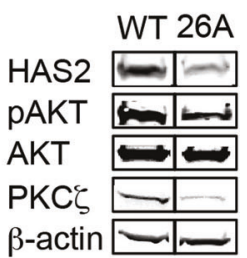

Interestingly, the levels of secreted CCL2 in the supernatant from WT PC3U cells was dramatically increased upon TNFo stimulation, but no such response was observed in the $26 \mathrm{~A}$ cell clone (Fig. 7d). These data suggest that $\mathrm{PKC} \zeta$ regulates the expression of lymphangiogenic factors in prostate cancer cells and the expression of CCL2, which is important for recruitment of macrophages and subsequent lymphangiogenesis in cancer progression and dissemination.
HA is a multifunctional molecule in the extracellular matrix and can interact with the cell surface receptor LYVE-1, which is expressed in the lymphatic vessels [21]. HA is synthesized by HASs (HAS1, HAS2, and HAS3). Lymphatic vessels drain a large number of HA molecules via LYVE-1; therefore, we investigated the expression of HASs. Interestingly, expression of HAS2 was apparently higher in the WT PC3U cells than in the 26A cell clone. We performed immunoblotting to detect the protein levels in 
Fig. $7 \mathrm{PKC} \zeta$ is involved in the regulation of aberrant lymphagiogenesis and lymphatic metastatic microenvironment. a qRT-PCR analysis for expression of $A N G 1, A N G 4, V E G F D, V E G F A, V E G F C$, and $F G F 2$ in WT PC3U cells and $P K C \zeta$-knockout 26A cell clone. $n=4$ independent experiment, results given as mean \pm S.E.M., $* p \leq 0.05$, students' $t$ tests. b Immunofluorescence staining of lymphatic vessel marker LYVE-1 and macrophage marker F4/80 in tumor tissue from the mouse xenografts model. Scale bar, $50 \mu \mathrm{m}$. c Analysis of CCL2 expression in WT PC3U cells and 26A cells by qRT-PCR, $n=4$ independent experiments, results given as mean \pm S.E.M., $* p \leq 0.05$, students' $t$ tests. d ELISA analysis for secretion of CCL2 in the media by WT PC3U cells or 26A cells treated with or without TNF $\alpha$ for $6 \mathrm{~h}$, and the results show the mean \pm S.D. from 3 independent experiments, $* p \leq 0.05$, one-way ANOVA. e qRT-PCR analysis for the expression of HAS1, HAS2, and HAS3 in WT PC3U cells and $P K C \zeta$-knockout 26A cells. $n=4$ independent experiment, results given as mean \pm S.E. M., * $p \leq 0.05$, students' $t$ tests. f Immunofluorescence analysis for the localization of HAS2 inside or outside lymphatic vessels (marker: LYVE-1) in WT tumors or 26A tumors from the mouse xenografts model. Scale bar, $50 \mu \mathrm{m}$. g Quantification of the intensity of HAS2 staining inside or outside lymphatic vessels from WT tumors (n $=8$ images) and 26A tumors ( $n=10$ images) by ImageJ software, given as mean \pm S.E.M., ${ }^{*} p \leq 0.05$, Mann-Whitney non-parametric test. h Western blot analysis of HAS2, pAKT, PKC $\zeta$ expression in tumor tissue in the mouse xenografts model. i Immunofluorescence staining of p65 in tumor tissue developed from WT PC3U cells or 26A cells in the mouse xenografts model. $\mathbf{j}$ Quantification of p65-staining in the nuclei (co-localization with DAPI) among 300 cells in the image of tumor tissue, WT ( $n=8$ images); 26A ( $n=10$ images), values were given as mean \pm S.E.M., $* p \leq 0.05$, Mann-Whitney non-parametric test. Dilutions for antibodies used in immunofluorescence; LYVE-1 (1:200), F4/80 (1:50), HAS2 and p65 (1:100). Dilutions for antibodies used in western blotting: HAS2 (1:200), pAKT, AKT, PKC $\zeta$ and $\beta$ actin $(1: 1000)$

tumors that developed from mouse xenografts. HAS2 was highly expressed in WT tumors but down-regulated in the tumors that developed from 26A cells (Fig. 7e). Coimmunofluorescent staining for HAS2 and LYVE-1 showed that a portion of prostate cancer cells that localized in the lymphatic vessels expressed dramatically higher levels of HAS2, with significant differences in the level of HAS2 in prostate cancer cells outside or inside the lymphatic vessels (Fig. 7f, g). Similar results were also obtained in PC3 tumors in the mouse xenograft model (Supplementary Figure 3). We also observed that the tumors that developed from the 26A cell clone had decreased AKT signaling (Fig. 7h), as expected and in line with our in vitro data presented in Fig. 2d. This indicates that more aggressive prostate cancer cells invade the lymphatic vessels, as they expressed more HAS2. As NF-kB signaling is known to regulate the expression of HAS2 [19], we detected activated p65 in the tumor tissue from xenografts by immunofluorescence. There was apparently more p65 in the nuclei of WT tumors, and clearly less nuclear p65 in the tumor tissues derived from the 26A cell clone (Fig. 7i, j). Taken together, these data indicate that $\mathrm{PKC} \zeta$ is important for the activation of $\mathrm{NF}-\kappa \mathrm{B}$, which then regulates the expression of
HAS2 and facilitates HA production and cancer cell dissemination via lymphatic drainage.

\section{Discussion}

In this study, we have investigated the correlation between expression of $\mathrm{PKC} \zeta$ and aggressivness of prostate cancer cells. As reported here, we observe that high levels of PKCל is regulating growth factor induced activation of AKT in response to TGF $\beta$, and activation of AKT and NFKB in response to EGF and $\mathrm{TNF} \alpha$, which also can explain their aggressiveness due to higher capability to proliferate and be invasive in vitro. The recent development of innovative genome editing technologies, such as ZFNs, TALENs, and CRISPR/Cas9, have shown the power of successful genetic manipulation, both in cell lines and human disease models [22-24]. By using ZFN technology or lentiviral short hairpin siRNA particles, the $P K C \zeta$ gene was specifically knocked out or knocked down from the aggressive castration-resistant human prostate cancer cell line PC3U and PC3 cells. This allowed us to study in detail, the molecular mechanisms whereby $\mathrm{PKC} \zeta$ modulates lymphatic metastasis of prostate cancer cells in vivo.

The role of PKC $\zeta$ in prostate cancer progression is complicated, as it exerts multiple functions in the regulation of different cell events temporally and spatially. Kim et al. reported that $\mathrm{PKC} \zeta$ suppresses prostate tumorigenesis in the early stage of neoplasia in a Pten ${ }^{+/}$mouse model [28]. However, PKC $\zeta$ promotes the aggressive phenotype of human prostate cancer cells [5] and facilitates the migration and invasion of prostate cancer cells via formation of the Par6-PKC $\zeta$ complex in the leading edge of membrane ruffles [14]. These studies suggest that PKC $\zeta$ likely has an oncogenic role that facilitates cancer cell invasion and metastasis in the later stages of prostate cancer progression. Here, we used a traditional xenograft model and found that $P K C \zeta$-knockout or knockdown from PC3U and PC3 cells prevented their invasive growth and lymphatic metastasis in mouse orthotopic xenografts. We found that this occurred due to $P K C \zeta$-knockout impairing angiogenesis and lymphangiogenesis during tumor development.

Interestingly, we found that $\mathrm{PKC} \zeta$ regulates prostate cancer cell secretion of substantive amounts of CCL2 and promote TAM recruitment. CCL2 was recently found to be a diagnostic, predictive, and prognostic biomarker of prostate cancer [29] and has been reported to be the most important chemokine for monocyte recruitment to prostate tumors $[17,30]$. Moreover, we also observed that PKC $\zeta$ knockout remarkably impaired the secretion of CCL2 by prostate cancer cells and less infiltration of monocyte/ macrophages into the tumors initiated from the 26A cell clone (Fig. 7b). Macrophages play a complex role in cancer 
depending on their phenotype, either promoting or inhibiting cancer progression [31]. In prostate cancer, the M2 macrophages are typically a "pro-tumor" phenotype, and the presence of tumor-associated M2 macrophages strongly correlates with angiogenesis, metastases and poorer patient outcomes [32]. In our orthotopic xenografts derived from the WT prostate cancer-initiated tumors, we found a number of macrophages in the invasive zone, which is important for continuous release of chemokines and lymphatic growth factors to facilitate tumor metastasis (Fig. 7b).

Both tumor cells and tumor-associated macrophages express lymphangiogenic factors [33]. VEGFC/D and VEGFR3 are the key pathways for lymphangiogenesis;[34] other important molecules include VEGFA and VEGFR2, angiopoietins ANG1, ANG2, ANG4, and TIE2, FGF2, BMP9, ALK1, Notch1, and ephrin B2 [35]. Interestingly, we found that $\mathrm{PKC} \zeta$ regulates the expression of $V E G F D$, $V E G F A, A N G 1$, and ANG4 in prostate cancer cells (Fig. 7a), which may facilitate the generation of aberrant lymphangiogenesis in tumors. However, the detailed mechanism, including which signaling pathway is involved in regulating the expression of lymphangiogenic factors via $\mathrm{PKC} \zeta$, is still unknown and needs to be further investigated. Some studies have reported that lymphatic density is an accurate independent predictor of poor survival and increased metastatic potential in human tumors [36-40]. Our study showed that $P K C \zeta$ knockout impaired lymphangiogenesis in two orthotopic prostate cancer models; both PC $3 \mathrm{U}$ and PC3, and that the lymphatic density was remarkably lower in tumors initiated from $P K C \zeta$-knockout cell clones, which correlated with less lymphatic metastasis in the in vivo model.

$\mathrm{NF}-\mathrm{KB}$ signaling is constitutively active in aggressive prostate cancer, playing a central role in modulating tumor stroma [41]. The activation of NF- $\kappa \mathrm{B}$ signaling controls the induction of cytokines and matrix metalloproteinases in tumor stroma, mediating tumor angiogenesis and metastasis $[42,43]$. Vigetti et al. reported that NF-אB also regulates the induction of HA in human endothelial cells [19]. Interestingly, we found that $\mathrm{PKC} \zeta$ is involved in the activation of NF- $\mathrm{KB}$ signaling in human prostate cancer xenografts, and that $\mathrm{PKC} \zeta$ regulates the expression of $\mathrm{HAS} 2$; thus, $\mathrm{PKC} \zeta$ might indirectly manipulate the amount of $\mathrm{HA}$ in the extracellular matrix, a factor that promotes prostate tumor growth and is associated with a poor prognosis [20]. HA mediates lymphatic drainage by binding LYVE-1. Through passive lymphatic drainage, cancer cells disseminate to the sentinel lymph nodes or distal organs. It was originally thought that tumors invade lymphatic vessels via passive drainage. However, recent data indicate a more complex and specific mechanism behind lymphatic metastasis. Lymphatic endothelial cells have been reported to highly express CCL21, whereas its receptor CCR7 is highly expressed in breast cancer cells and melanoma cells and predicted to be the mechanism by which breast cancer and melanoma preferentially metastasize to lymph nodes $[33,44]$. However, if there is a specific interaction between prostate cancer cells and the lymphatic endothelium, or if other molecules specifically mediate this interaction still needs to be investigated. Our study proposes that $\mathrm{PKC} \zeta$ maybe represents a novel drug target in prostate cancer to prevent tumor progression and lymph node metastasis.

\section{Materials and methods}

\section{Cell culture}

The human prostate cancer cell line PC3 and human lung cancer cell line A549 were purchased from ECACC (Salisbury, UK). The human prostate cancer cell line $\mathrm{LNCaP}$ were purchased from ATCC (Manassas, USA). PC3U cells were originally derived from PC3 cells and express more TGF $\beta$ receptors than PC3 [45]. The cancer cell lines were grown in RPMI-1640 with $10 \%$ fetal bovine serum (FBS) and L-glutamine (Sigma, St. Louis, MO, USA). The human immortalized normal prostate cell line RPWE1 were from ATCC (Manassas, USA) and cultured in the Keratinocyte Serum-Free Medium with bovine pituitary and human recombinant epidermal growth factor (Gibco-Thermo Scientific, Waltham, MA, USA). The cells were starved 12-18 $\mathrm{h}$ in medium supplemented with $1 \%$ FBS before EGF, TGF $\beta$ (Prospec, Ness-Ziona, Israel), and TNF $\alpha$ (GibcoThermo Scientific) stimulation at a concentration of $10 \mathrm{ng} /$ $\mathrm{ml}$. The cell lines were routinely tested for mycoplasma contamination and a panel of pathogens, following the guidelines of Umeå University Animal Care Committee.

\section{Antibodies and reagents}

The antibodies against PKC $\zeta$, pAKT, AKT, TRAF6, APPL1, pERK, ERK, pSmad2, Smad2, P65, LaminA, were purchased from Cell Signaling Technology, Inc. (Beverly, MA, USA) and used at 1:1000 dilution for Western blotting. HAS2 (Santa Cruz, CA, USA) was used at 1:200, and $\beta$-actin and $\beta$-tubulin (Sigma, St. Louis, MO, USA) was used at 1:1000 for Western blotting. Antibodies against LYVE-1, GFP, F4/80 (Abcam, UK), Ki67 was used at 1:500 dilution (Dako, Denmark), Alexafluor 488 and Alexafluor 555 (Invitrogen, Oregon, USA) were used for immune-staining. 4,6-Diamidino-2-phenylindole dihydrochloride (DAPI) was from Merck, (Darmstadt, Germany). Pefabloc was from Roche (Mannheim,Germany), and PageRuler prestained protein ladder was from Thermo Scientific. 


\section{Western blotting}

The cultured cells was washed once with ice-cold PBS and lysed in ice-cold lysis buffer $(150 \mathrm{mM} \mathrm{NaCl}, 50 \mathrm{mM}$ Tris $\mathrm{pH} 8.0,0.5 \%(\mathrm{v} / \mathrm{v})$ DOC, $1 \%(\mathrm{v} / \mathrm{v})$ NP40, $10 \%(\mathrm{v} / \mathrm{v})$ glycerol, $1 \mathrm{mM}$ aprotinin, $1 \mathrm{mM}$ Pefabloc and $2 \mathrm{mM}$ sodium orthovanadate). The tumor tissue from mouse experiments was lysed in the above lysis buffer with Tissuelyser II (Qiagen, Germany). After centrifugation, the supernatants were collected and protein concentrations were determined by BCA protein measurement kit (Thermo Scientific). Equal amount of protein from total cell lysate was run in SDS-PAGE and transfered on to polyvinylidine difluoride membranes. The membranes were blocked for $1 \mathrm{~h}$ with $5 \%$ BSA in TBS-T and then incubated with specific antibodies overnight at $4{ }^{\circ} \mathrm{C}$. Then the membranes were washed 3 times with TBS-T, incubated for $1 \mathrm{~h}$ with a secondary horseradish peroxidase-conjugated antibody and developed with ECLWestern blotting detection reagent and detected with Amersham Imager RBG system (GE Healthcare, Buckinghamshire, UK).

\section{XCELLigence real-time cell proliferation assay}

Experiments were carried out using the RTCA DP xCELLigence Analyzer and E16 xCELLigence plate (ACEA Biosciences, Inc. San Diego, CA, USA). The E16 plates were prepared by addition of complete media $(50 \mu \mathrm{l})$ to each well. After equilibration to $37^{\circ} \mathrm{C}$, plates were inserted into the xCELLigence, and the base-line impedance was measured to ensure the wells and connections are working. Then 20000 freshly split cells in $50 \mu$ media were added into each well, and the xCELLigence system start to detect changes in impedance over time, every $5 \mathrm{~min}$ in the first $5 \mathrm{~h}$, and then every $15 \mathrm{~min}$ in $72 \mathrm{~h}$. Inhibitor was added into the cells $1 \mathrm{~h}$ after seeding. Data was calculated using RTCA software 2.0, supplied with the instrument.

\section{Invasion assay}

Invasion assay was performed with the CytoSelect ${ }^{\mathrm{TM}}$ Cell Invasion Assay kit (Cell Biolabs, Inc., San Diego, CA). The collagen layer of the cell culture inserts were rehydrated in $300 \mu \mathrm{L}$ serum-free RPMI-1640 media, and $1 \times 10^{6}$ cells were seeded into the upper side of the chambers in $1 \%$ serum RPMI-1640. Lower wells of the invasion plates were filled with $500 \mu \mathrm{l}$ RPMI with $10 \%$ FBS. Non-invasive cells were removed from the upper chamber after growing for 24 $\mathrm{h}$, and the invasive cells were photographed with a Leica DMR light microscope after staining with crystal violet cell stain solution. Colorimetric quantification was performed by transfer inserts into $200 \mu \mathrm{L}$ of extraction solution for $10 \mathrm{~min}$. Optical density (O.D.) at $560 \mathrm{~nm}$ was measured in a 96-well plate by Multiscan FC Microplate Photometer (Thermo Scientific).

\section{Generation of PKCZ-deficient cell line}

CompoZr knockout Zinc Finger Nucleases (ZFN) Kit designed for $P K C \zeta$-knockout was purchased from SigmaAldrich (St. Louis, MO, USA). According to the manufacturers protocol, PC3U cells were seeded in a 6-well plate 1 day before, and then two ZFN plasmids were transfected into the cells at 50\% confluence with Fugene 6 (Promega, Madison WI, USA). After transfection for 2 days, part of cells were harvested for DNA analysis, and part of cells were diluted for a single cell culture in a 96well plate until single clones were obtained. These cell clones were cultured and stored at $-160{ }^{\circ} \mathrm{C}$ for further confirmation.

\section{shRNA lentiviral particles transduction and selection of the stable clones}

PKC $\zeta$ shRNA lentiviral particles, control shRNA lentiviral particles, and copGFP control lentiviral particles, were purchased from Santa Cruz Biotechnology (Texas, USA). Following the manufacturers instruction, the target cells were seeded in a 12 -well plate for $24 \mathrm{~h}$ before the transfection, and became approximately $50 \%$ confluent on the day of infection. After the media was replaced by the transfection media with Polybrene (Santa Cruz) at a concentration of $5 \mu \mathrm{g} / \mathrm{ml}$, the shRNA lentiviral particles were added into the cells. The transfection media was removed after $24 \mathrm{~h}$, and then the cells were cultured in complete media for $48 \mathrm{~h}$. To select the stable clones expressing the shRNA, the infected cells were cultured in the media with Puromycin at $5 \mu \mathrm{g} / \mathrm{ml}$ for 2 weeks, and then several colonies were picked up and expanded for validation of knock down of endogenous $\mathrm{PKC}$.

\section{PCR and Single-strand conformation polymorphism (SSCP) analysis}

Genomic DNA was exacted from cell lines with the Genomic DNA Miniprep Kit (Sigma-Aldrich). ZFN cutting site was amplified with forward primer $5^{\prime}-3^{\prime}$ AATATGCCCCACGGTAACA, reverse primer $5^{\prime}-3^{\prime}$ ATAAGCATCTGTGGCCAACC for PCR amplification $\left(95^{\circ} \mathrm{C}\right.$ for $5 \mathrm{~min}, 30$ cycles from $95^{\circ} \mathrm{C}$ for $30 \mathrm{~s}, 57^{\circ} \mathrm{C}$ for 30 s to $72{ }^{\circ} \mathrm{C}$ for $30 \mathrm{~s}$, final extension for $7 \mathrm{~min}$ at $72{ }^{\circ} \mathrm{C}$, hold at $4{ }^{\circ} \mathrm{C}$ ). PCR products were mixed with equal volume of SSCP loading buffer $(0.05 \%$ bromophenol blue, $0.05 \%$ xylene cyanol, $95 \%$ formamide, $10 \mathrm{mM}$ EDTA), denatured at $95{ }^{\circ} \mathrm{C}$ for $5 \mathrm{~min}$, rapidly cooled on ice, and then loaded on a precast $12.5 \%$ acrylamide gel. 


\section{Cel-1 assay or Surveyor nuclease assay}

A total of $10 \mu \mathrm{l}$ of PCR product from above was used in a slow temperature decreasing program: $95^{\circ} \mathrm{C}$ for $10 \mathrm{~min}$, decreasing the temperature form $95^{\circ} \mathrm{C}$ to $85^{\circ} \mathrm{C}$ by $-2.0^{\circ} \mathrm{C} /$ $\mathrm{s}$, keep the temperature at $85^{\circ} \mathrm{C}$ for $1 \mathrm{~min}$, decreasing the temperature from 85 to $25^{\circ} \mathrm{C}$ by $-0.3{ }^{\circ} \mathrm{C} / \mathrm{s}$, and hold at $4{ }^{\circ} \mathrm{C}$. Thereafter, SURVEYOR Nuclease (Transgenomic, Omaha, USA) was added to the denatured and re-annealed PCR products to incubate for $2 \mathrm{~h}$, and then the digestion products were separated on the $10 \%$ polyacrylamide gel in $1 \times$ TBE buffer, and visualized by silver staining method.

\section{Sequencing analysis}

Genomic DNA from Cel-1 assay positive cells was purified and ZFN cutting site was PCR amplified as described above. Sequencing PCR (BigDye Teminator v 3.1 cycle sequencing kit) was performed using this amplified PCR product. The sequencing results were analyzed on Sequence Scanner v 1.0 software.

\section{Immunofluorescence staining for cultured cells}

Cells were grown on the sterile glass microscopy slides in a 6-well plate under the indicated condition. The slides were washed 4 times with PBS, fixed in 4\% paraformaldehyde for $30 \mathrm{~min}$ at room temperature, washed 4 times in PBS and subsequently permeabilized in $0.2 \%$ Triton X-100 in PBS for $10 \mathrm{~min}$, and washed again 4 times in PBS, blocked in 10 $\mathrm{mM}$ glycine overnight. Then, the slides were incubated with primary antibody anti-Ki67 (1:500) in a humid chamber for $1 \mathrm{~h}$ at room temperature. After washing with PBS, the slides were incubated with fluorescent dye labeled second antibodies for $45 \mathrm{~min}$ hours at room temperature, and then with DAPI for $5 \mathrm{~min}$. Thereafter, the mount medium was added on the slides for imaging. The samples were analyzed in a fluorescence microscope (Axioplan 2; Carl Zeiss Microimaging, Inc.) with a digital camera (C4742-95; Hamamatsu), using a Plan-neofluar $\times 63$ objective lens (Carl Zeiss MicroImaging, Inc.); photography was performed at room temperature. Primary images were acquired with the camra's QED software.

\section{Xenografts animal experiment}

All mouse experiments were carried out in strict accordance with the guidelines of Umeå University Animal Care Committee, and under the conditions and procedures approved by the Umea Ethical Animal Review Board (ID: A19-13, A7-18). Five- to 6-weeks old male athymic nude mice (Hsd:Athymic Nude- Foxn $1^{\text {nu }}$, Harlan) were purchased from Harlan laboratories, UK, and maintained at the animal facility at Umeå University. For the orthotopic injection, $2 \%$ isoflurane were used to anesthetize the mice and the prostates were exposed with an abdominal incision, and then $1 \times 10^{5} \mathrm{PC} 3 \mathrm{U}$ cells, $3 \times 10^{5} \mathrm{PC} 3$, or $3 \times 10^{5} \mathrm{LNCaP}$ cells were injected into the prostate. In total 80 mice were used in this study, with ten mice randomly included in each group. The mice were monitored and body weight was measured twice a week. There were totally 5 mice dead before the planned sacrifice, therefore, they were not included in the analysis. After injection of PC3U cells for 4 weeks, or PC3 or LNCaP cells for 6 weeks, the animals were sacrificed. Tumors and regional lymph nodes were resected, and weighted. Small portions of tumor tissues were froozen in liquid nitrogen for protein and RNA extraction. The remaining tumor tissues and lymph nodes were fixed in formalin and embedded in paraffin for morphology evaluation with light microscopy.

\section{Immunohistochemistry staining for paraffin- embedded sections}

Paraffin-embedded sections were rehydrated in xylene 2 times each for $10 \mathrm{~min}, 100 \%$ ethanol for $10 \mathrm{~min}, 95 \%, 80 \%$, $70 \%$ ethanol and deionized $\mathrm{H}_{2} \mathrm{O}$ each for $5 \mathrm{~min}$, and then in PBS for $10 \mathrm{~min}$. Thereafter the sections were treated with Antigen Retrieval Reagent (R\&D System, MN, USA) at 95 ${ }^{\circ} \mathrm{C}$ for $5 \mathrm{~min}$, rinsed with PBS. Then the sections were kept in $0.75 \% \mathrm{H}_{2} \mathrm{O}_{2} / 75 \%$ methanol for $30 \mathrm{~min}$, washed twice with PBS, and blocket in 5\% normal goat serum for $1 \mathrm{~h}$ at room temperature. The sections were incubated with primary antibodies overnight at $4{ }^{\circ} \mathrm{C}$, LYVE-1 (1:200). After being washed with PBS 3 times each for $5 \mathrm{~min}$, the sections incubated with secondary antibody (DAKO envision system, Denmark) for $45 \mathrm{~min}$ at room temperature followed by three washes in PBS. Then, the sections were developed with AEC (Vector Laboratories, Burlingame, CA, USA), counterstained with hematoxylin and mounted in aqueous mounting medium (Vector Laboratories). Digital images for IHC were acquired by scanning with Pannoramic 250 Flash II (3DHistech, Hungary), and then examined by two pathologists at Umeå University Hospital, and analyzed by ImageJ software.

\section{Immunofluorescence staining for paraffin- embedded sections}

Sections from animal experiments were deparaffinized and retrieved as described above, and thereafter blocked in $1 \%$ horse serum in PBS for $1 \mathrm{~h}$ at room temperature, and then incubated with primary antibodies overnight at $4{ }^{\circ} \mathrm{C}$, LYVE-1 (1:200), GFP (1:200), F4/80 (1:50), HAS2 (1:100), p65 (1:100). After being washed with PBS 3 times each for $5 \mathrm{~min}$, the sections were incubated with 
NorthernLights secondary antibody (R\&D) for $45 \mathrm{~min}$ at room temperature. Then the sections were washed with PBS 3 times each for 5 min, mounted with mounting media with DAPI and visualized with a fluorescence microscope (Axioplan 2; Carl Zeiss Microimaging, Inc.).

\section{Quantitative assessment}

For the digital images, a semi-automated algorithm was used to extract detailed morphometric data on the diameter, area, numbers of vessels, and distribution of different sizes of vessels by using modified software (Image J, National Institutes of Health, Bethesda, MD). Finally the total area and volume was summed up for each tumor. The data was expressed a vascular segment numbers, representing the total numbers of vessels of specified diameters, and counted in all reformatted cross-sections. The intensity of HAS2 were also measured by ImageJ software, and mean pixel intensity values (Gray-scale values) were calculated to compare the intensity of staining.

\section{Conditioned medium preparation and ELISA}

WT and 26A PC3U cells were cultured with or without TNF $\alpha$ stimulation for $6 \mathrm{~h}$. The conditioned medium was collected, centrifuged at $300 \times g$ for $10 \mathrm{~min}$, and then centrifuged with Ultracel-3K Centrifugal filters (Merck Millipore Ltd, Tullagreen Carrigtwohill Co, Ireland) at $4000 \times g$ for $30 \mathrm{~min}$. Secretion of CCL2 into the medium was determined by using the DuoSet ELISA -Human CCL2/ MCP-1 kit (R\&D Systems, Minneapolis, MN, USA), according to the manufacturer's protocols. Optical density (O.D.) at $450 \mathrm{~nm}$ was measured in a 96-well plate by Multiscan FC Microplate Photometer (Thermo Scientific).

\section{Whole exome sequencing (WES) and data analysis}

Genome DNA was purified with Allprep DNA/RNA/protein mini kit (Qiagen, Cat.80004), subjected to WES at Novogene (Novogene Bioinformatics Institute, Beijing, China). Single nucleotide polymorphisms (SNPs) and small insertions/deletions (indels) were identified using GATK HaplotypeCaller (version 4.0).

\section{RNA preparation and qRT-PCR}

RNA from WT and 26A PC3U cells was extracted using AllPrep DNA/RNA/Protein Mini Kit (QIAGEN, Cat. 80004) following manufacturer's instructions. Purified total RNA $(2 \mu \mathrm{g})$ was used as a template for cDNA synthesis with Thermoscript RT-PCR system (Invitrogen Cat.11146016) according to the manufacturer's instruction.
Purified cDNA was amplified and measured with Stratagene RT-PCR system, and SYBR Green (Applied Biosystems Cat.4385612) was used for detection of PCR products. The following primers $\left(5^{\prime}-3^{\prime}\right)$ were used for qRT-PCR.

ANG1 FP GGGCCCAGTTACTCCTTACG ANG1 RP TGTGAACTCAAACGGCTCCA ANG4 FP TGTGACATGGAGGGTGTTCG ANG4 RP CCCACCATTGGTCATGGGAA VEGFA FP AGGAGGGCAGAATCATCACG VEGFA RP CTGGAAGATGTCCACCAGGG VEGFC FP TGGGGAAGGAGTTTGGAGTC VEGFC RP GTTACTGGTTTGGGGCCTTG VEGFD FP TCTGAACAGCAGATCAGGGC VEGFD RP AACCTAGTGGACCGATGGGA FGF2 FP TCTATGTCGTGGAAGCACCG FGF2 RP GAAGGGTCTCCCGCATACTC CCL2 FP TCTCAAACTGAAGCTCGCACT CCL2 RP GGGAATGAAGGTGGCTGCTA HAS1 FP GAGCCTCTTCGCGTACCTG HAS1 RP CCTCCTGGTAGGCGGAGAT HAS2 FP CTCTTTTGGACTGTATGGTGCC HAS2 RP AGGGTAGGTTAGCCTTTTCACA HAS3 FP CAGCCTATGTGACGGGCTAC HAS3 RP CCTCCTGGTATGCGGCAAT

\section{Statistical analysis}

Statistical analysis were performed with a two-tailed unpaired Student's $t$ test for two groups comparision or one-way ANOVA for multiple comparision to determine if treatments groups were significantly different from each other. The non-parametric Mann-Whitney $U$ test was used in vivo data. $p \leq 0.05$ was considered as statistically significant. Error bars represent standard deviation of the mean, unless otherwise is indicated. Statistical tests and the number of repeats are described in the figure legends.

Acknowledgements We would like to acknowledge the National Genomics Infrastructure (NGI)/Uppsala Genome Center and UPPMAX for providing assistance in massive parallel sequencing and computational infrastructure. Work performed at the NGI/Uppsala Genome Center was funded by the RFI/VR and Science for Life Laboratory, Sweden. We would like to thank Dr. Jeanette Tångrot for the exome sequencing analysis and support from the Bioinformatics Infrastructure for Life Sciences (BILS) and Dr. Xiaolian Gu for valuable advices on data achieved from whole genome sequencing of PC3 and PC3U cells. We acknowledge the skillful technical assistance performed by Pernilla Andersson and Susanne Gidlund at Department of Medical Bioscience, Umeå University. This work was supported by grants from the Swedish Medical Research Council (K2016-02513), the Swedish Cancer Society (CAN 2017/544; 2016/387), ALF-VLL464591 and ALF-VLL-738911, the Knut and Alice Wallenberg Foundation (2012.0090), the Cancer Research Foundation in Northern Sweden, Lion's Cancer Research Foundation, and Umeå University. 


\section{Compliance with ethical standards}

Conflict of interest The authors declare that they have no conflict of interest.

Publisher's note: Springer Nature remains neutral with regard to jurisdictional claims in published maps and institutional affiliations.

Open Access This article is licensed under a Creative Commons Attribution 4.0 International License, which permits use, sharing, adaptation, distribution and reproduction in any medium or format, as long as you give appropriate credit to the original author(s) and the source, provide a link to the Creative Commons license, and indicate if changes were made. The images or other third party material in this article are included in the article's Creative Commons license, unless indicated otherwise in a credit line to the material. If material is not included in the article's Creative Commons license and your intended use is not permitted by statutory regulation or exceeds the permitted use, you will need to obtain permission directly from the copyright holder. To view a copy of this license, visit http://creativecommons. org/licenses/by/4.0/.

\section{References}

1. Siegel RL, Miller KD, Jemal A. Cancer statistics, 2016. CA Cancer J Clin. 2016;66:7-30.

2. Daneshmand $\mathrm{S}$, et al. Prognosis of patients with lymph node positive prostate cancer following radical prostatectomy: longterm results. J Urol. 2004;172(6 Pt 1):2252-5.

3. Datta $\mathrm{K}$, et al. Mechanism of lymph node metastasis in prostate cancer. Future Oncol. 2010;6:823-36.

4. Hirai T, Chida K. Protein kinase Czeta (PKCzeta): activation mechanisms and cellular functions. J Biochem. 2003;133:1-7.

5. Yao S, et al. PRKC-zeta expression promotes the aggressive phenotype of human prostate cancer cells and is a novel target for therapeutic intervention. Genes Cancer. 2010;1:444-64.

6. Sun R, et al. Protein kinase $\mathrm{C}$ zeta is required for epidermal growth factor-induced chemotaxis of human breast cancer cells. Cancer Res. 2005;65:1433-41.

7. Guo $\mathrm{H}$, et al. Reduction of protein kinase $\mathrm{C}$ zeta inhibits migration and invasion of human glioblastoma cells. J Neurochem. 2009; 109:203-13.

8. Esteve PO, et al. Protein kinase C-zeta regulates transcription of the matrix metalloproteinase- 9 gene induced by IL-1 and TNFalpha in glioma cells via NF-kappa B. J Biol Chem. 2002;277:35150-5.

9. Evans JD, et al. Expression patterns of protein kinase C isoenzymes are characteristically modulated in chronic pancreatitis and pancreatic cancer. Am J Clin Pathol. 2003;119:392-402.

10. Berra E, et al. Evidence for a role of MEK and MAPK during signal transduction by protein kinase $\mathrm{C}$ zeta. EMBO J. 1995;14:6157-63.

11. Diaz-Meco MT, Moscat J. MEK5, a new target of the atypical protein kinase $\mathrm{C}$ isoforms in mitogenic signaling. Mol Cell Biol. 2001;21:1218-27.

12. Yang $M$, et al. E3 ubiquitin ligase CHIP facilitates Toll-like receptor signaling by recruiting and polyubiquitinating $\mathrm{Src}$ and atypical PKC\{zeta\}. J Exp Med. 2011;208:2099-112.

13. Leitges M, et al. Targeted disruption of the zetaPKC gene results in the impairment of the NF-kappaB pathway. Mol Cell. 2001;8:771-80

14. Mu Y, et al. TGFbeta-induced phosphorylation of Par6 promotes migration and invasion in prostate cancer cells. $\mathrm{Br} \mathrm{J}$ Cancer. 2015;112:1223-31.
15. Joyce JA, Pollard JW. Microenvironmental regulation of metastasis. Nat Rev Cancer. 2009;9:239-52.

16. Condeelis J, Pollard JW. Macrophages: obligate partners for tumor cell migration, invasion, and metastasis. Cell. 2006;124:263-6.

17. Lissbrant IF, et al. Tumor associated macrophages in human prostate cancer: relation to clinicopathological variables and survival. Int J Oncol. 2000;17:445-51.

18. Jiang D, Liang J, Noble PW. Hyaluronan in tissue injury and repair. Annu Rev Cell Dev Biol. 2007;23:435-61.

19. Vigetti D, et al. Proinflammatory cytokines induce hyaluronan synthesis and monocyte adhesion in human endothelial cells through hyaluronan synthase 2 (HAS2) and the nuclear factorkappaB (NF-kappaB) pathway. J Biol Chem. 2010;285:24639-45.

20. Josefsson A, et al. Prostate cancer increases hyaluronan in surrounding nonmalignant stroma, and this response is associated with tumor growth and an unfavorable outcome. Am J Pathol. 2011;179:1961-8.

21. Monslow J, Govindaraju P, Pure E. Hyaluronan - a functional and structural sweet spot in the tissue microenvironment. Front Immunol. 2015;6:231.

22. Brown AJ, et al. Whole-rat conditional gene knockout via genome editing. Nat Methods. 2013;10:638-40.

23. Sato K, et al. Generation of a nonhuman primate model of severe combined immunodeficiency using highly efficient genome editing. Cell Stem Cell. 2016;19:127-38.

24. Mali $\mathrm{P}$, et al. RNA-guided human genome engineering via Cas9. Science. 2013;339:823-6.

25. Hamidi A, et al. TGF-beta promotes PI3K-AKT signaling and prostate cancer cell migration through the TRAF6-mediated ubiquitylation of p85alpha. Sci Signal. 2017;10:486.

26. Avraamides CJ, Garmy-Susini B, Varner JA. Integrins in angiogenesis and lymphangiogenesis. Nat Rev Cancer. 2008;8:604-17.

27. Qian BZ, et al. CCL2 recruits inflammatory monocytes to facilitate breast-tumour metastasis. Nature. 2011;475:222-5.

28. Kim JY, et al. c-Myc phosphorylation by PKCzeta represses prostate tumorigenesis. Proc Natl Acad Sci USA. 2013;110:641823.

29. Izumi K, et al. Serum chemokine (CC motif) ligand 2 level as a diagnostic, predictive, and prognostic biomarker for prostate cancer. Oncotarget. 2016;7:8389-98.

30. Halin $\mathrm{S}$, et al. Extratumoral macrophages promote tumor and vascular growth in an orthotopic rat prostate tumor model. Neoplasia. 2009;11:177-86.

31. Noy R, Pollard JW. Tumor-associated macrophages: from mechanisms to therapy. Immunity. 2014;41:49-61.

32. Shiao SL, Chu GC, Chung LW. Regulation of prostate cancer progression by the tumor microenvironment. Cancer Lett. 2016;380:340-8.

33. Stacker SA, et al. Lymphangiogenesis and lymphatic vessel remodelling in cancer. Nat Rev Cancer. 2014;14:159-72.

34. Tammela T, Alitalo K. Lymphangiogenesis: Molecular mechanisms and future promise. Cell. 2010;140:460-76.

35. Zheng W, Aspelund A, Alitalo K. Lymphangiogenic factors, mechanisms, and applications. J Clin Invest. 2014;124:878-87.

36. Shayan R, Achen MG, Stacker SA. Lymphatic vessels in cancer metastasis: bridging the gaps. Carcinogenesis. 2006;27:1729-38.

37. Dadras SS, et al. Tumor lymphangiogenesis: a novel prognostic indicator for cutaneous melanoma metastasis and survival. Am J Pathol. 2003;162:1951-60.

38. Kyzas PA, et al. Evidence for lymphangiogenesis and its prognostic implications in head and neck squamous cell carcinoma. J Pathol. 2005;206:170-7.

39. Yokoyama Y, et al. Vascular endothelial growth factor-D is an independent prognostic factor in epithelial ovarian carcinoma. $\mathrm{Br} \mathrm{J}$ Cancer. 2003;88:237-44. 
40. Zeng Y, et al. Lymphatic vessel density and lymph node metastasis in prostate cancer. Prostate. 2005;65:222-30.

41. Nguyen DP, et al. Recent insights into NF-kappaB signalling pathways and the link between inflammation and prostate cancer. BJU Int. 2014;114:168-76.

42. Huang S, et al. Blockade of NF-kappaB activity in human prostate cancer cells is associated with suppression of angiogenesis, invasion, and metastasis. Oncogene. 2001;20:4188-97.

43. Hagemann T, et al. Regulation of macrophage function in tumors: the multifaceted role of NF-kappaB. Blood. 2009;113:3139-46.
44. Pang MF, et al. TGF-beta1-induced EMT promotes targeted migration of breast cancer cells through the lymphatic system by the activation of CCR7/CCL21-mediated chemotaxis. Oncogene. 2016;35:748-60.

45. Franzen P, Ichijo H, Miyazono K. Different signals mediate transforming growth factor-beta 1-induced growth inhibition and extracellular matrix production in prostatic carcinoma cells. Exp Cell Res. 1993;207:1-7. 